\title{
RADIATIVE TRANSITIONS FOR THREE LOWEST CONFIGURATIONS OF TUNGSTEN IONS $\mathrm{W}^{38+}-\mathrm{W}^{43+}$
}

\author{
R. Karpuškienè, P. Bogdanovich ${ }^{\star}$, and R. Kisielius \\ Institute of Theoretical Physics and Astronomy, Vilnius University, Sauletekio 3, LT-10257 Vilnius, Lithuania \\ E-mail: rasa.karpuskiene@tfai.vu.lt
}

Received 4 April 2017; revised 18 May 2017; accepted 15 June 2017

\begin{abstract}
The $a b$ initio quasirelativistic approximation was used to derive transition data for the multicharged tungsten ions $\mathrm{W}^{38+}-\mathrm{W}^{43+}$ with an open $4 \mathrm{p}$ shell. The configuration interaction method with transformed radial orbitals was applied to include electron correlation effects. The relativistic effects were taken into account in the Breit-Pauli approximation for the quasirelativistic Hartree-Fock radial orbitals. The level energies $E$, radiative lifetimes $\tau$, and Landé $g$-factors were calculated for the $4 \mathrm{~s}^{2} 4 \mathrm{p}^{N}, 4 \mathrm{~s}^{2} 4 \mathrm{p}^{N-1} 4 \mathrm{~d}$, and $4 \mathrm{~s} 4 \mathrm{p}^{N+1}$ configurations of six tungsten ions. The radiative transition wavelengths $\lambda$, spontaneous emission transition probabilities $A$ and their uncertainties for the electric dipole, electric quadrupole, electric octupole, magnetic dipole and magnetic quadrupole transitions among the levels of these configurations are presented.
\end{abstract}

Keywords: tungsten, level energies, radiative rates, Landé $g$-factors, lifetimes

PACS: $31.10 .+Z$, 31.15.ag, 32.70.Cs

\section{Introduction}

Metallic tungsten has some unique physical features making it a suitable material for divertor walls of tokamak devices. Although it resists vaporization, highly-charged ions of tungsten can emerge in fusion plasma and consequently decrease its temperature due to radiation. Therefore both experimental and theoretical physicists show a surging interest in tungsten spectroscopic properties [1-3]. The theoretical and experimental studies of the tungsten ions are important in fusion plasma research, but available spectroscopic data for the ions with an open $4 \mathrm{p}^{N}$ shell are incomplete. The basic atomic processes in tungsten ions $\mathrm{W}^{37+}-\mathrm{W}^{46+}$ have been investigated using the relativistic methods in [4]. Our earlier studies of the highly-charged tungsten ions (see, e.g. [5, 6) clearly demonstrated a suitability of the quasirelativistic approach (QR) for the calculation of spectroscopic properties for highly-charged tungsten ions with open $4 \mathrm{~d}^{N}$ shells. In a similar way, the spectroscopic parameters of the $\mathrm{W}^{39+}$ ion with the ground configuration $4 \mathrm{~s}^{2} 4 \mathrm{p}^{5}$ were determined and their accuracy was assessed in our previous work [7]. In that study the level energies and radiative transition parameters were calculated and compared with available experimental [8-10] and theoretical data from other sources $[9,11,12$,

As our initial efforts to produce high-quality spectroscopic data for the tungsten ions with an open $4 \mathrm{p}^{N}$ shell by utilizing the QR approach have been fruitful, in the present paper we expand that by a comprehensive calculation of radiative

\footnotetext{
* The community of Lithuanian physicists experienced a loss on 10 August 2017, when Pavel Bogdanovich unexpectedly died. He was a talented disciple of Adolfas Jucys - the father of modern theory of an atom in Lithuania, and remained the principal developer of computational atomic physics throughout his career. Pavel was also the soul of Physics Olympiads for pupils in Lithuania and the skilled mentor of national teams at corresponding international events.
} 
transition parameters for these tungsten ions. The aim of the present paper is to determine the spectroscopic parameters of the radiative transitions including the high-multipole order ones and to evaluate the uncertainties of the determined transition probabilities and wavelengths. Spectroscopic data for the levels of the excited configurations $4 \mathrm{~s}^{2} 4 \mathrm{p}^{N}, 4 \mathrm{~s}^{2} 4 \mathrm{p}^{N-1} 4 \mathrm{~d}$, and $4 \mathrm{~s} 4 \mathrm{p}^{N+1}$ of the tungsten ions have not been investigated previously, except for a few lines. This work presents a complete set of the spectroscopic parameters determined using the same theoretical approach for each investigated ion. The level energies for such ions determined in the QR approach are presented in [13]. That work contains the overview of various studies of the tungsten ions and the comparison of our QR results with available data $[8,11$, 12, 14-19]. In the very recent work [20] the multiconfiguration Dirac-Hartree-Fock method (MCDHF) is applied to determine level energies and radiative lifetimes for eight $\mathrm{Kr}$-like ions, including the $\mathrm{W}^{38+}$ ion.

The current work tabulates the level energies of the ions $\mathrm{W}^{38+}-\mathrm{W}^{43+}$ along with the level radiative lifetimes and Landé $g$-factors. Another part of data presents the electric dipole (E1), electric quadrupole (E2), electric octupole (E3), magnetic dipole (M1), and magnetic quadrupole (M2) transitions for the $\mathrm{W}^{38+}-\mathrm{W}^{43+}$ ions.

As already mentioned before, we compared our results with available experimental and theoretical data. Such a comparison serves as one of the quality criteria for new calculated data [21]. In the current study we present a significantly larger set of the spectroscopic data compared to earlier works. Therefore we have no means to compare a big part of new data and hence we need to assess the uncertainties of our data. Based on ideas given in [12, 21, 22], we evaluate our QR results by considering one of the accuracy aspects, i.e. by assessing how the accuracy of the calculated level energies influences the uncertainties of the $\mathrm{QR}$ transition probabilities. Further we list these determined uncertainties for the radiative transition parameters considering various types of multipole electron transitions.

In Section 2 we provide a short description of our calculation method and the QR approach. Since the adopted approximation completely matches that described in [13], we provide only a brief summary of our method here. The produced data and their accuracy assessment are discussed in Section 3 where our results are compared with available experimental data and theoretical data from other authors.

\section{Calculation method}

The calculation of transition parameters springs from eigenfunctions and eigenvalues determined for energy levels. Therefore one needs to determine the high-rank matrices of the energy operator on the basis of all investigated and most admixed configurations. The basis of radial orbitals (RO) is generated for that purpose. The formation of this basis is performed in a way ensuring an effective convergence of the configuration interaction (CI) method. By diagonalizing the constructed matrices (Hamiltonian matrices), one can determine the abovementioned parameters of energy levels. They are further applied to determine the parameters of radiative electron multipole transitions or other spectroscopic parameters.

As already mentioned in Section 1, the quasirelativistic approximation is adopted here. That method was already successfully applied in our previous studies of multicharged tungsten ions. The general principles and method of our QR approach are presented in [23].

In the present work we investigate the three lowest configurations of the tungsten ions $\mathrm{W}^{38+}-\mathrm{W}^{43+}$ : the ground configuration $[\mathrm{Ar}] 4 \mathrm{~s}^{2} 4 \mathrm{p}^{N}$, and two excited $[\mathrm{Ar}] 4 \mathrm{~s}^{2} 4 \mathrm{p}^{N-1} 4 \mathrm{~d}$ and $[\mathrm{Ar}] 4 \mathrm{~s} 4 \mathrm{p}^{N+1}$, $N=1, \ldots, 6$. All possible radiative transitions among the levels of these configurations are determined. At the start of the investigation for each ion, the quasirelativistic Hartree-Fock (QRHF) equations [24, 25] are solved and RO are determined for the ground configuration. Further the QRHF equations are solved for $\mathrm{RO}$ of the $4 \mathrm{~d}$ and $4 \mathrm{f}$ electrons in the frozen-core $4 \mathrm{~s}^{2} 4 \mathrm{p}^{N-1}$ potential. The one-electron radial orbitals for the virtually excited ( $5 \leq n \leq 10, l<\mathrm{n})$ electrons are described by the quasirelativistic transformed radial orbitals (TRO) [23]. The same set of radial orbitals is adopted both for even and odd configurations. Consequently, we avoid the problem of non-orthogonality in the calculation of radiative transition parameters. Such an approach is well suited for the investigated multicharged tungsten ions as 
outer electrons in a strong nuclear potential are weakly affected by electron distribution in the inner shells. We apply the Breit-Pauli operator specifically adopted for our employed QR approximation for the formation of energy matrices [23]. As our experience indicates, the adoption of such an approach in the QR calculations ensures a comprehensive inclusion of the relativistic effects.

The correlation effects are included within the CI approximation. The TRO method was specifically designed for that approximation. The admixed configurations are generated by promoting one or two electrons from the $3 l$ and $4 l$ shells of the adjusted configurations to all states that can be generated using an available set of the radial orbitals. Since different types of the virtual excitation are utilized here, and the set of the radial orbitals is large, the number of the admixed configurations is also huge. Fortunately, not all of the constructed admixed configurations are important in calculations. Only strongly-interacting configurations are included in the CI wave function expansion, and the total number of configuration state functions (CSFs) is reduced by the methods presented in [26, 27]. These methods were applied in all our previous investigations. The utilization of this method for the investigated tungsten ions and specific calculation details are widely discussed in [13]. The explicit numbers of the constructed admixed configurations and generated CSFs for each investigated ion are also listed there.

The determined level energies for each tungsten ion were consistently compared to the exist- ing experimental data and available calculations from other authors in [13]. It was concluded there that the accuracy of the QR level energies is no worse than that of other calculations. Moreover, in many cases the accuracy of the QR data is better compared to other theoretical results. This allows us to assume that our calculated transition parameters are also substantially accurate. Based on these comparisons, we can assess uncertainties of the calculated level energies. In the next section we apply the determined uncertainties of the level energies to evaluate the uncertainties of transition data.

The properties of the investigated energy levels for the $\mathrm{W}^{38+}-\mathrm{W}^{43+}$ ions are listed in Table 1 . The level indices $K$ are separate for each individual ion; they are further applied in the description of radiative transitions. We list level designations in the $L S$ coupling and the total angular momenta $J$ to indicate a particular level for each ion. The level designations $L S$ are assigned rather formally by the configuration state function (CSF) having the largest contribution in the CI wavefunction expansion for a particular level. We employ the $L S$ coupling in our calculations although this coupling is not well-suited for multicharged ions because of a strong spin-orbit interaction. Therefore the CI wavefunction expansion includes a large number of CSF. Furthermore, some levels of the same configuration have non-unique formal LSJ parameters (or level designations). To distinguish among them, we introduce additional subscripts "a" at their notations.

Table 1. Level indices $K$, level designations $L S$ and their total angular momenta $J$, level energies $E$ (in $10^{3} \mathrm{~cm}^{-1}$ ), Landé $g$-factors, and radiative lifetimes $\tau$ (in $10^{-9} \mathrm{~s}$ ) for the $\mathrm{W}^{38+}-\mathrm{W}^{43+}$ ions.

\begin{tabular}{c|c|c|c|c|c}
\hline$K$ & $L S$ & $J$ & $E$ & $g$ & $\tau$ \\
\hline \multicolumn{7}{c}{$\mathrm{W}^{38+}$} & 0 & 0 & 0.000 & - \\
\hline 1 & $4 \mathrm{~s}^{2} 4 \mathrm{p}^{6} \mathrm{~S}$ & 0 & 1208 & 0.000 & - \\
\hline 2 & $4 \mathrm{~s}^{2} 4 \mathrm{p}^{5} 4 \mathrm{~d}^{3} \mathrm{P}$ & 1 & 1249 & 1.248 & $4.48 \mathrm{E}-01$ \\
\hline 3 & $4 \mathrm{~s}^{2} 4 \mathrm{p}^{5} 4 \mathrm{~d}^{3} \mathrm{P}$ & 3 & 1276 & 1.075 & $4.56 \mathrm{E}+07$ \\
\hline 4 & $4 \mathrm{~s}^{2} 4 \mathrm{p}^{5} 4 \mathrm{~d}^{3} \mathrm{~F}$ & 2 & 1284 & 1.091 & $1.98 \mathrm{E}+06$ \\
\hline 5 & $4 \mathrm{~s}^{2} 4 \mathrm{p}^{5} 4 \mathrm{~d}^{3} \mathrm{D}$ & 2 & 1389 & 1.250 & $5.87 \mathrm{E}+04$ \\
\hline 6 & $4 \mathrm{~s}^{2} 4 \mathrm{p}^{5} 4 \mathrm{~d}^{3} \mathrm{~F}$ & 4 & 1408 & 1.200 & $1.98 \mathrm{E}+04$ \\
\hline 7 & $4 \mathrm{~s}^{2} 4 \mathrm{p}^{5} 4 \mathrm{~d}^{1} \mathrm{D}$ & 2 & 1452 & 1.229 & $1.97 \mathrm{E}+04$ \\
\hline 8 & $4 \mathrm{~s}^{2} 4 \mathrm{p}^{5} 4 \mathrm{~d}^{3} \mathrm{D}$ & 3 & 1573 & 0.879 & $1.65 \mathrm{E}-03$ \\
\hline 9 & $4 \mathrm{~s}^{2} 4 \mathrm{p}^{5} 4 \mathrm{~d}^{3} \mathrm{D}$ & 1 & 1983 & 0.776 & $1.48 \mathrm{E}+02$ \\
\hline 10 & $4 \mathrm{~s}^{2} 4 \mathrm{p}^{5} 4 \mathrm{~d}^{3} \mathrm{~F}$ & 2 & & &
\end{tabular}


Table 1. (continued)

\begin{tabular}{|c|c|c|c|c|c|}
\hline$K$ & $L S$ & $J$ & $E$ & $g$ & $\tau$ \\
\hline 11 & $4 s^{2} 4 p^{5} 4 d^{3} P$ & 2 & 2130 & 1.267 & $1.50 \mathrm{E}+02$ \\
\hline 12 & $4 s^{2} 4 p^{5} 4 d^{1} P$ & 1 & 2138 & 0.874 & 4.67E-04 \\
\hline 13 & $4 s^{2} 4 p^{5} 4 d^{3} F_{a}$ & 3 & 2152 & 1.112 & $1.35 \mathrm{E}+02$ \\
\hline \multicolumn{6}{|c|}{$\mathrm{W}^{39+}$} \\
\hline 1 & $4 s^{2} 4 p^{52} \mathrm{P}$ & 1.5 & 0 & 1.333 & - \\
\hline 2 & $4 s^{2} 4 p^{52} \mathrm{P}$ & 0.5 & 748 & 0.667 & $1.27 \mathrm{E}+02$ \\
\hline 3 & $4 s^{2} 4 p^{4}\left({ }^{3} P\right) 4 d^{4} D$ & 1.5 & 1222 & 1.182 & $3.94 \mathrm{E}-01$ \\
\hline 4 & $4 s^{2} 4 \mathrm{p}^{4}\left({ }^{3} \mathrm{P}\right) 4 \mathrm{~d}^{4} \mathrm{P}$ & 0.5 & 1239 & 1.673 & $9.05 \mathrm{E}-02$ \\
\hline 5 & $4 s^{2} 4 p^{4}\left({ }^{3} \mathrm{P}\right) 4 \mathrm{~d}^{4} \mathrm{D}$ & 2.5 & 1240 & 1.222 & $7.85 \mathrm{E}-01$ \\
\hline 6 & $4 s^{2} 4 \mathrm{p}^{4}\left({ }^{3} \mathrm{P}\right) 4 \mathrm{~d}^{4} \mathrm{~F}$ & 3.5 & 1263 & 1.135 & $3.69 \mathrm{E}+06$ \\
\hline 7 & $4 s^{2} 4 p^{4}\left({ }^{1} S\right) 4 d^{2} D$ & 1.5 & 1328 & 0.869 & $4.72 \mathrm{E}+00$ \\
\hline 8 & $4 s^{2} 4 p^{4}\left({ }^{3} \mathrm{P}\right) 4 \mathrm{~d}^{4} \mathrm{D}$ & 0.5 & 1377 & 1.293 & $2.42 \mathrm{E}-01$ \\
\hline 9 & $4 s^{2} 4 \mathrm{p}^{4}\left({ }^{3} \mathrm{P}\right) 4 \mathrm{~d}^{2} \mathrm{P}$ & 3.5 & 1377 & 1.249 & $2.66 \mathrm{E}+04$ \\
\hline 10 & $4 s^{2} 4 \mathrm{p}^{4}\left({ }^{3} \mathrm{P}\right) 4 \mathrm{~d}^{4} \mathrm{~F}$ & 4.5 & 1387 & 1.266 & $4.38 \mathrm{E}+04$ \\
\hline 11 & $4 s^{2} 4 p^{4}\left({ }^{1} S\right) 4 d^{2} D$ & 2.5 & 1491 & 1.222 & $8.94 \mathrm{E}+02$ \\
\hline 12 & $4 s^{2} 4 p^{4}\left({ }^{3} P\right) 4 d^{4} P$ & 1.5 & 1529 & 1.171 & $2.54 \mathrm{E}-03$ \\
\hline 13 & $4 s^{2} 4 p^{4}\left({ }^{3} P\right) 4 d^{2} D$ & 2.5 & 1554 & 1.148 & $1.84 \mathrm{E}-03$ \\
\hline 14 & $4 s 4 p^{6}{ }^{2} S$ & 0.5 & 1624 & 1.983 & $1.59 \mathrm{E}-03$ \\
\hline 15 & $4 \mathrm{~s}^{2} 4 \mathrm{p}^{4}\left({ }^{3} \mathrm{P}\right) 4 \mathrm{~d}^{4} \mathrm{D}$ & 0.5 & 1916 & 0.207 & $1.19 \mathrm{E}-01$ \\
\hline 16 & $4 s^{2} 4 p^{4}\left({ }^{3} P\right) 4 d^{4} D_{a}$ & 1.5 & 1954 & 0.982 & $5.61 \mathrm{E}-01$ \\
\hline 17 & $4 \mathrm{~s}^{2} 4 \mathrm{p}^{4}\left({ }^{3} \mathrm{P}\right) 4 \mathrm{~d}^{4} \mathrm{~F}$ & 2.5 & 1989 & 0.997 & $2.35 \mathrm{E}-02$ \\
\hline 18 & $4 s^{2} 4 p^{4}\left({ }^{1} D\right) 4 d^{2} G$ & 3.5 & 1998 & 1.009 & $2.66 \mathrm{E}+02$ \\
\hline 19 & $4 \mathrm{~s}^{2} 4 \mathrm{p}^{4}\left({ }^{3} \mathrm{P}\right) 4 \mathrm{~d}^{4} \mathrm{D}_{\mathrm{a}}$ & 3.5 & 2090 & 1.299 & $1.42 \mathrm{E}+02$ \\
\hline 20 & $4 \mathrm{~s}^{2} 4 \mathrm{p}^{4}\left({ }^{1} \mathrm{D}\right) 4 \mathrm{~d}^{2} \mathrm{P}$ & 1.5 & 2116 & 1.447 & $2.77 \mathrm{E}-03$ \\
\hline 21 & $4 s^{2} 4 p^{4}\left({ }^{1} D\right) 4 d^{2} S$ & 0.5 & 2126 & 1.823 & $4.20 \mathrm{E}-04$ \\
\hline 22 & $4 \mathrm{~s}^{2} 4 \mathrm{p}^{4}\left({ }^{3} \mathrm{P}\right) 4 \mathrm{~d}^{2} \mathrm{D}_{\mathrm{a}}$ & 2.5 & 2132 & 1.188 & $5.38 \mathrm{E}-04$ \\
\hline 23 & $4 s^{2} 4 \mathrm{p}^{4}\left({ }^{3} \mathrm{P}\right) 4 \mathrm{~d}^{2} \mathrm{P}$ & 1.5 & 2134 & 1.086 & 7.25E-04 \\
\hline 24 & $4 s^{2} 4 p^{4}\left({ }^{3} \mathrm{P}\right) 4 \mathrm{~d}^{2} \mathrm{~F}$ & 2.5 & 2138 & 1.140 & $1.11 \mathrm{E}+01$ \\
\hline 25 & $4 s^{2} 4 p^{4}\left({ }^{1} D\right) 4 d^{2} G$ & 4.5 & 2141 & 1.179 & $2.52 \mathrm{E}+02$ \\
\hline 26 & $4 \mathrm{~s}^{2} 4 \mathrm{p}^{4}\left({ }^{1} \mathrm{D}\right) 4 \mathrm{~d}^{2} \mathrm{D}$ & 2.5 & 2165 & 1.207 & $9.35 \mathrm{E}-03$ \\
\hline 27 & $4 \mathrm{~s}^{2} 4 \mathrm{p}^{4}\left({ }^{1} \mathrm{D}\right) 4 \mathrm{~d}^{2} \mathrm{~F}$ & 3.5 & 2197 & 1.148 & $2.13 \mathrm{E}+02$ \\
\hline 28 & $4 s^{2} 4 p^{4}\left({ }^{3} P\right) 4 d^{2} D$ & 1.5 & 2313 & 0.836 & $1.32 \mathrm{E}-03$ \\
\hline 29 & $4 \mathrm{~s}^{2} 4 \mathrm{p}^{4}\left({ }^{3} \mathrm{P}\right) 4 \mathrm{~d}^{2} \mathrm{P}_{\mathrm{a}}$ & 0.5 & 2358 & 1.019 & $8.14 \mathrm{E}-04$ \\
\hline 30 & $4 \mathrm{~s}^{2} 4 \mathrm{p}^{4}\left({ }^{1} \mathrm{~S}\right) 4 \mathrm{~d}^{2} \mathrm{D}_{\mathrm{a}}$ & 1.5 & 2846 & 0.828 & $6.51 \mathrm{E}-04$ \\
\hline 31 & $4 \mathrm{~s}^{2} 4 \mathrm{p}^{4}\left({ }^{1} \mathrm{~S}\right) 4 \mathrm{~d}^{2} \mathrm{D}_{\mathrm{a}}$ & 2.5 & 2908 & 1.190 & $7.46 \mathrm{E}-01$ \\
\hline \multicolumn{6}{|c|}{$\mathrm{W}^{40+}$} \\
\hline 1 & $4 \mathrm{~s}^{2} 4 \mathrm{p}^{43} \mathrm{P}$ & 2 & 0 & 1.349 & - \\
\hline 3 & $4 s^{2} 4 p^{43} \mathrm{P}$ & 1 & 744 & 1.500 & $1.16 \mathrm{E}+02$ \\
\hline 4 & $4 s^{2} 4 p^{41} \mathrm{D}$ & 2 & 777 & 1.151 & $2.32 \mathrm{E}+02$ \\
\hline 5 & $4 s^{2} 4 \mathrm{p}^{3}\left({ }^{2} \mathrm{P}\right) 4 \mathrm{~d}^{3} \mathrm{D}$ & 2 & 1265 & 1.062 & $1.23 \mathrm{E}-01$ \\
\hline 6 & $4 s^{2} 4 p^{3}\left({ }^{2} \mathrm{P}\right) 4 \mathrm{~d}^{3} \mathrm{P}$ & 1 & 1286 & 1.153 & $7.74 \mathrm{E}-02$ \\
\hline 7 & $4 s^{2} 4 p^{3}\left({ }^{2} \mathrm{P}\right) 4 d^{3} \mathrm{P}$ & 0 & 1289 & 0.000 & $3.45 \mathrm{E}+01$ \\
\hline
\end{tabular}


Table 1. (continued)

\begin{tabular}{|c|c|c|c|c|c|}
\hline$K$ & $L S$ & $J$ & $E$ & $g$ & $\tau$ \\
\hline 8 & $4 \mathrm{~s}^{2} 4 \mathrm{p}^{3}\left({ }^{2} \mathrm{P}\right) 4 \mathrm{~d}^{3} \mathrm{~F}$ & 3 & 1296 & 1.131 & $9.88 \mathrm{E}+00$ \\
\hline 9 & $4 s 4 p^{53} \mathrm{P}$ & 2 & 1418 & 1.323 & $6.79 \mathrm{E}-02$ \\
\hline 10 & $4 s^{2} 4 \mathrm{p}^{3}\left({ }^{2} \mathrm{P}\right) 4 \mathrm{~d}^{3} \mathrm{~F}$ & 4 & 1431 & 1.272 & $2.66 \mathrm{E}+04$ \\
\hline 11 & $4 s^{2} 4 p^{43} \mathrm{P}$ & 0 & 1546 & 0.000 & $5.38 \mathrm{E}+01$ \\
\hline 12 & $4 \mathrm{~s}^{2} 4 \mathrm{p}^{3}\left({ }^{2} \mathrm{P}\right) 4 \mathrm{~d}^{3} \mathrm{D}$ & 3 & 1546 & 1.180 & $2.24 \mathrm{E}-03$ \\
\hline 13 & $4 s^{2} 4 \mathrm{p}^{3}\left({ }^{2} \mathrm{P}\right) 4 \mathrm{~d}^{1} \mathrm{P}$ & 1 & 1562 & 1.130 & $3.85 \mathrm{E}-03$ \\
\hline 14 & $4 s 4 p^{53} \mathrm{P}_{\mathrm{a}}$ & 2 & 1597 & 1.420 & $2.24 \mathrm{E}-03$ \\
\hline 15 & $4 \mathrm{~s} 4 \mathrm{p}^{51} \mathrm{P}$ & 1 & 1682 & 1.098 & $1.61 \mathrm{E}-03$ \\
\hline 16 & $4 s^{2} 4 p^{3}\left({ }^{4} S\right) 4 d^{5} D$ & 1 & 1969 & 0.990 & $1.92 \mathrm{E}-02$ \\
\hline 17 & $4 s^{2} 4 p^{3}\left({ }^{4} S\right) 4 d^{5} D$ & 0 & 1970 & 0.000 & $1.01 \mathrm{E}-01$ \\
\hline 19 & $4 s^{2} 4 p^{3}\left({ }^{2} \mathrm{D}\right) 4 d^{3} \mathrm{~F}$ & 3 & 2001 & 1.102 & $5.59 \mathrm{E}-02$ \\
\hline 20 & $4 \mathrm{~s}^{2} 4 \mathrm{p}^{3}\left({ }^{2} \mathrm{D}\right) 4 \mathrm{~d}^{3} \mathrm{G}$ & 4 & 2037 & 1.065 & $7.28 \mathrm{E}+02$ \\
\hline 21 & $4 s^{2} 4 \mathrm{p}^{3}\left({ }^{2} \mathrm{P}\right) 4 \mathrm{~d}^{3} \mathrm{~F}$ & 2 & 2080 & 0.846 & $8.71 \mathrm{E}-03$ \\
\hline 22 & $4 s^{2} 4 p^{3}\left({ }^{2} D\right) 4 d^{3} D$ & 3 & 2118 & 1.359 & $6.77 \mathrm{E}-03$ \\
\hline 23 & $4 s^{2} 4 p^{3}\left({ }^{4} S\right) 4 d^{5} D$ & 4 & 2127 & 1.298 & $1.55 \mathrm{E}+02$ \\
\hline 24 & $4 \mathrm{~s}^{2} 4 \mathrm{p}^{3}\left({ }^{2} \mathrm{D}\right) 4 \mathrm{~d}^{1} \mathrm{~S}$ & 0 & 2149 & 0.000 & $5.43 \mathrm{E}+00$ \\
\hline 25 & $4 \mathrm{~s}^{2} 4 \mathrm{p}^{3}\left({ }^{2} \mathrm{D}\right) 4 \mathrm{~d}^{1} \mathrm{P}$ & 1 & 2150 & 1.002 & $1.74 \mathrm{E}-03$ \\
\hline 26 & $4 \mathrm{~s}^{2} 4 \mathrm{p}^{3}\left({ }^{2} \mathrm{D}\right) 4 \mathrm{~d}^{3} \mathrm{P}$ & 2 & 2153 & 1.282 & $5.62 \mathrm{E}-04$ \\
\hline 27 & $4 s^{2} 4 p^{3}\left({ }^{4} S\right) 4 d^{3} D$ & 3 & 2157 & 1.157 & $6.04 \mathrm{E}-04$ \\
\hline 28 & $4 \mathrm{~s}^{2} 4 \mathrm{p}^{3}\left({ }^{2} \mathrm{D}\right) 4 \mathrm{~d}^{3} \mathrm{P}$ & 1 & 2159 & 1.517 & $7.09 \mathrm{E}-04$ \\
\hline 29 & $4 s^{2} 4 \mathrm{p}^{3}\left({ }^{2} \mathrm{D}\right) 4 \mathrm{~d}^{3} \mathrm{~F}$ & 4 & 2173 & 1.181 & $6.85 \mathrm{E}+02$ \\
\hline 30 & $4 s^{2} 4 p^{3}\left({ }^{2} D\right) 4 d^{3} G$ & 5 & 2188 & 1.200 & $6.88 \mathrm{E}+02$ \\
\hline 31 & $4 s^{2} 4 p^{3}\left({ }^{2} P\right) 4 d^{3} D$ & 1 & 2223 & 0.956 & $5.74 \mathrm{E}-04$ \\
\hline 32 & $4 s^{2} 4 p^{3}\left({ }^{2} P\right) 4 d^{3} \mathrm{P}$ & 2 & 2251 & 1.277 & $1.08 \mathrm{E}-01$ \\
\hline 33 & $4 \mathrm{~s}^{2} 4 \mathrm{p}^{3}\left({ }^{2} \mathrm{P}\right) 4 \mathrm{~d}^{3} \mathrm{~F}_{\mathrm{a}}$ & 3 & 2278 & 1.130 & 5.93E-01 \\
\hline 34 & $4 s^{2} 4 p^{3}\left({ }^{4} S\right) 4 d^{3} D$ & 2 & 2311 & 1.076 & $1.84 \mathrm{E}-03$ \\
\hline 35 & $4 s^{2} 4 p^{3}\left({ }^{4} S\right) 4 d^{3} D$ & 1 & 2324 & 1.180 & $1.22 \mathrm{E}-03$ \\
\hline 36 & $4 \mathrm{~s}^{2} 4 \mathrm{p}^{3}\left({ }^{2} \mathrm{D}\right) 4 \mathrm{~d}^{1} \mathrm{~F}$ & 3 & 2350 & 1.070 & $1.51 \mathrm{E}-03$ \\
\hline 37 & $4 \mathrm{~s}^{2} 4 \mathrm{p}^{3}\left({ }^{2} \mathrm{D}\right) 4 \mathrm{~d}^{1} \mathrm{D}$ & 2 & 2372 & 1.225 & $9.19 \mathrm{E}-04$ \\
\hline 38 & $4 s 4 p^{53} \mathrm{P}$ & 0 & 2373 & 0.000 & $1.47 \mathrm{E}-03$ \\
\hline 39 & $4 \mathrm{~s} 4 \mathrm{p}^{53} \mathrm{P}$ & 1 & 2455 & 1.319 & $8.45 \mathrm{E}-04$ \\
\hline 40 & $4 \mathrm{~s}^{2} 4 \mathrm{p}^{3}\left({ }^{2} \mathrm{P}\right) 4 \mathrm{~d}^{3} \mathrm{P}_{\mathrm{a}}$ & 0 & 2856 & 0.000 & $5.38 \mathrm{E}-04$ \\
\hline 41 & $4 \mathrm{~s}^{2} 4 \mathrm{p}^{3}\left({ }^{2} \mathrm{P}\right) 4 \mathrm{~d}^{3} \mathrm{P}_{\mathrm{a}}$ & 1 & 2875 & 1.213 & $6.45 \mathrm{E}-04$ \\
\hline 42 & $4 s^{2} 4 p^{3}\left({ }^{2} P\right) 4 d^{1} F$ & 3 & 2902 & 1.076 & $6.57 \mathrm{E}-04$ \\
\hline 43 & $4 \mathrm{~s}^{2} 4 \mathrm{p}^{3}\left({ }^{2} \mathrm{P}\right) 4 \mathrm{~d}^{3} \mathrm{D}_{\mathrm{a}}$ & 2 & 2904 & 1.116 & 7.49E-04 \\
\hline 44 & $4 s^{2} 4 \mathrm{p}^{3}\left({ }^{2} \mathrm{P}\right) 4 \mathrm{~d}^{3} \mathrm{~F}_{\mathrm{a}}$ & 4 & 2937 & 1.233 & $7.72 \mathrm{E}+01$ \\
\hline 45 & $4 \mathrm{~s}^{2} 4 \mathrm{p}^{3}\left({ }^{2} \mathrm{P}\right) 4 \mathrm{~d}^{1} \mathrm{D}$ & 2 & 2956 & 1.167 & $2.03 \mathrm{E}-02$ \\
\hline 46 & $4 \mathrm{~s}^{2} 4 \mathrm{p}^{3}\left({ }^{2} \mathrm{P}\right) 4 \mathrm{~d}^{3} \mathrm{D}_{\mathrm{a}}$ & 3 & 3000 & 1.212 & $1.54 \mathrm{E}-01$ \\
\hline 47 & $4 \mathrm{~s}^{2} 4 \mathrm{p}^{3}\left({ }^{2} \mathrm{P}\right) 4 \mathrm{~d}^{1} \mathrm{P}_{\mathrm{a}}$ & 1 & 3171 & 0.942 & $8.21 \mathrm{E}-04$ \\
\hline \multicolumn{6}{|c|}{$\mathrm{W}^{41+}$} \\
\hline 1 & $4 s^{2} 4 p^{32} \mathrm{P}$ & 1.5 & 0 & 1.371 & - \\
\hline 2 & $4 s^{2} 4 p^{34} S$ & 1.5 & 714 & 1.457 & $1.41 \mathrm{E}+02$ \\
\hline
\end{tabular}


Table 1. (continued)

\begin{tabular}{|c|c|c|c|c|c|}
\hline$K$ & $L S$ & $J$ & $E$ & $g$ & $\tau$ \\
\hline 3 & $4 s^{2} 4 p^{32} \mathrm{D}$ & 2.5 & 759 & 1.200 & $6.71 \mathrm{E}+02$ \\
\hline 4 & $4 s^{2} 4 p^{32} \mathrm{P}$ & 0.5 & 817 & 0.667 & $2.07 \mathrm{E}+02$ \\
\hline 5 & $4 s^{2} 4 p^{2}\left({ }^{3} \mathrm{P}\right) 4 \mathrm{~d}^{4} \mathrm{~F}$ & 1.5 & 1261 & 0.796 & $8.68 \mathrm{E}-02$ \\
\hline 6 & $4 \mathrm{~s} 4 \mathrm{p}^{4}\left({ }^{3} \mathrm{P}\right){ }^{4} \mathrm{P}$ & 2.5 & 1434 & 1.337 & $2.02 \mathrm{E}-02$ \\
\hline 7 & $4 \mathrm{~s}^{2} 4 \mathrm{p}^{32} \mathrm{P}_{\mathrm{a}}$ & 1.5 & 1538 & 1.305 & $7.17 \mathrm{E}+01$ \\
\hline 8 & $4 s 4 p^{4}\left({ }^{3} \mathrm{P}\right){ }^{4} \mathrm{P}_{\mathrm{a}}$ & 2.5 & 1548 & 1.355 & $3.28 \mathrm{E}-03$ \\
\hline 9 & $4 s 4 p^{4}\left({ }^{1} S\right)^{2} S$ & 0.5 & 1633 & 2.121 & $3.81 \mathrm{E}-03$ \\
\hline 10 & $4 \mathrm{~s} 4 \mathrm{p}^{4}\left({ }^{3} \mathrm{P}\right){ }^{2} \mathrm{P}$ & 1.5 & 1651 & 1.173 & $1.97 \mathrm{E}-03$ \\
\hline 11 & $4 s^{2} 4 \mathrm{p}^{2}\left({ }^{3} \mathrm{P}\right) 4 \mathrm{~d}^{4} \mathrm{~F}$ & 2.5 & 1972 & 0.967 & $1.05 \mathrm{E}-01$ \\
\hline 12 & $4 \mathrm{~s}^{2} 4 \mathrm{p}^{2}\left({ }^{3} \mathrm{P}\right) 4 \mathrm{~d}^{4} \mathrm{~F}_{\mathrm{a}}$ & 1.5 & 1974 & 0.922 & $1.63 \mathrm{E}-02$ \\
\hline 13 & $4 s^{2} 4 p^{2}\left({ }^{3} P\right) 4 d^{4} D$ & 0.5 & 1976 & 0.218 & 9.49E-02 \\
\hline 14 & $4 s^{2} 4 p^{2}\left({ }^{1} D\right) 4 d^{2} G$ & 3.5 & 2017 & 1.055 & $4.04 \mathrm{E}+00$ \\
\hline 15 & $4 s^{2} 4 p^{2}\left({ }^{3} P\right) 4 d^{4} D$ & 3.5 & 2128 & 1.314 & $1.33 \mathrm{E}+00$ \\
\hline 16 & $4 s^{2} 4 \mathrm{p}^{2}\left({ }^{3} \mathrm{P}\right) 4 \mathrm{~d}^{4} \mathrm{P}$ & 2.5 & 2130 & 1.213 & $6.63 \mathrm{E}-04$ \\
\hline 17 & $4 \mathrm{~s} 4 \mathrm{p}^{4}\left({ }^{3} \mathrm{P}\right){ }^{4} \mathrm{P}$ & 1.5 & 2131 & 1.465 & $4.35 \mathrm{E}-02$ \\
\hline 18 & $4 s^{2} 4 p^{2}\left({ }^{1} D\right) 4 d^{2} D$ & 1.5 & 2139 & 1.200 & $5.12 \mathrm{E}-04$ \\
\hline 19 & $4 s^{2} 4 \mathrm{p}^{2}\left({ }^{3} \mathrm{P}\right) 4 \mathrm{~d}^{4} \mathrm{P}$ & 0.5 & 2146 & 1.688 & $6.17 \mathrm{E}-04$ \\
\hline 20 & $4 \mathrm{~s}^{2} 4 \mathrm{p}^{2}\left({ }^{1} \mathrm{D}\right) 4 \mathrm{~d}^{2} \mathrm{D}$ & 2.5 & 2164 & 1.182 & 8.87E-03 \\
\hline 21 & $4 s^{2} 4 p^{2}\left({ }^{1} D\right) 4 d^{2} G$ & 4.5 & 2177 & 1.200 & $6.61 \mathrm{E}+03$ \\
\hline 22 & $4 \mathrm{~s}^{2} 4 \mathrm{p}^{2}\left({ }^{1} \mathrm{D}\right) 4 \mathrm{~d}^{2} \mathrm{~F}$ & 3.5 & 2288 & 1.113 & $2.13 \mathrm{E}-03$ \\
\hline 23 & $4 \mathrm{~s}^{2} 4 \mathrm{p}^{2}\left({ }^{3} \mathrm{P}\right) 4 \mathrm{~d}^{4} \mathrm{P}_{\mathrm{a}}$ & 2.5 & 2290 & 1.226 & $1.20 \mathrm{E}-03$ \\
\hline 24 & $4 \mathrm{~s}^{2} 4 \mathrm{p}^{2}\left({ }^{3} \mathrm{P}\right) 4 \mathrm{~d}^{2} \mathrm{D}$ & 1.5 & 2292 & 1.071 & $2.94 \mathrm{E}-03$ \\
\hline 25 & $4 s^{2} 4 p^{2}\left({ }^{1} D\right) 4 d^{2} S$ & 0.5 & 2303 & 1.355 & $2.40 \mathrm{E}-03$ \\
\hline 26 & $4 s 4 p^{4}\left({ }^{3} \mathrm{P}\right){ }^{4} \mathrm{P}_{\mathrm{a}}$ & 1.5 & 2338 & 1.312 & $1.62 \mathrm{E}-03$ \\
\hline 27 & $4 s 4 p^{4}\left({ }^{1} \mathrm{D}\right){ }^{2} \mathrm{D}$ & 2.5 & 2382 & 1.272 & $1.55 \mathrm{E}-03$ \\
\hline 28 & $4 s 4 p^{4}\left({ }^{3} \mathrm{P}\right){ }^{2} \mathrm{P}_{\mathrm{a}}$ & 1.5 & 2461 & 1.088 & $1.01 \mathrm{E}-03$ \\
\hline 29 & $4 \mathrm{~s} 4 \mathrm{p}^{4}\left({ }^{3} \mathrm{P}\right){ }^{2} \mathrm{P}$ & 0.5 & 2464 & 1.266 & $8.79 \mathrm{E}-04$ \\
\hline 30 & $4 \mathrm{~s}^{2} 4 \mathrm{p}^{2}\left({ }^{1} \mathrm{D}\right) 4 \mathrm{~d}^{2} \mathrm{D}_{\mathrm{a}}$ & 1.5 & 2842 & 1.184 & $6.22 \mathrm{E}-04$ \\
\hline 31 & $4 \mathrm{~s}^{2} 4 \mathrm{p}^{2}\left({ }^{3} \mathrm{P}\right) 4 \mathrm{~d}^{4} \mathrm{P}_{\mathrm{a}}$ & 0.5 & 2845 & 1.556 & $6.95 \mathrm{E}-04$ \\
\hline 32 & $4 s^{2} 4 p^{2}\left({ }^{3} \mathrm{P}\right) 4 \mathrm{~d}^{4} \mathrm{D}$ & 2.5 & 2849 & 1.199 & $7.24 \mathrm{E}-04$ \\
\hline 33 & $4 \mathrm{~s}^{2} 4 \mathrm{p}^{2}\left({ }^{3} \mathrm{P}\right) 4 \mathrm{~d}^{2} \mathrm{~F}$ & 3.5 & 2867 & 1.158 & $8.08 \mathrm{E}-04$ \\
\hline 34 & $4 s^{2} 4 p^{2}\left({ }^{3} \mathrm{P}\right) 4 d^{2} \mathrm{~F}_{a}$ & 3.5 & 2909 & 1.202 & $8.53 \mathrm{E}-03$ \\
\hline 35 & $4 \mathrm{~s}^{2} 4 \mathrm{p}^{2}\left({ }^{3} \mathrm{P}\right) 4 \mathrm{~d}^{4} \mathrm{~F}$ & 4.5 & 2916 & 1.245 & $1.22 \mathrm{E}+02$ \\
\hline 36 & $4 \mathrm{~s}^{2} 4 \mathrm{p}^{2}\left({ }^{3} \mathrm{P}\right) 4 \mathrm{~d}^{2} \mathrm{P}$ & 0.5 & 2918 & 1.359 & $5.06 \mathrm{E}-02$ \\
\hline 37 & $4 s^{2} 4 p^{2}\left({ }^{1} S\right) 4 d^{2} D$ & 1.5 & 2935 & 0.884 & $7.65 \mathrm{E}-04$ \\
\hline 38 & $4 s^{2} 4 p^{2}\left({ }^{1} S\right) 4 d^{2} D$ & 2.5 & 3026 & 1.208 & $5.24 \mathrm{E}-01$ \\
\hline 39 & $4 \mathrm{~s}^{2} 4 \mathrm{p}^{2}\left({ }^{3} \mathrm{P}\right) 4 \mathrm{~d}^{2} \mathrm{D}_{\mathrm{a}}$ & 1.5 & 3097 & 1.172 & $1.29 \mathrm{E}-03$ \\
\hline 40 & $4 \mathrm{~s}^{2} 4 \mathrm{p}^{2}\left({ }^{3} \mathrm{P}\right) 4 \mathrm{~d}^{2} \mathrm{D}$ & 2.5 & 3132 & 1.156 & $9.41 \mathrm{E}-04$ \\
\hline 41 & $4 s 4 p^{4}\left({ }^{1} S\right){ }^{2} S_{a}$ & 0.5 & 3246 & 1.770 & $6.86 \mathrm{E}-04$ \\
\hline \multicolumn{6}{|c|}{$\mathrm{W}^{42+}$} \\
\hline 1 & $4 s^{2} 4 p^{23} \mathrm{P}$ & 0 & 0 & 0.000 & - \\
\hline 2 & $4 s^{2} 4 p^{23} P$ & 1 & 734 & 1.500 & $2.00 \mathrm{E}+02$ \\
\hline
\end{tabular}


Table 1. (continued)

\begin{tabular}{|c|c|c|c|c|c|}
\hline$K$ & $L S$ & $J$ & $E$ & $g$ & $\tau$ \\
\hline 3 & $4 s^{2} 4 p^{21} \mathrm{D}$ & 2 & 772 & 1.183 & $6.45 \mathrm{E}+03$ \\
\hline 4 & $4 s^{4} \mathrm{p}^{3}\left({ }^{2} \mathrm{P}\right){ }^{3} \mathrm{P}$ & 2 & 1515 & 1.574 & $4.14 \mathrm{E}-02$ \\
\hline 5 & $4 s^{2} 4 p^{2}{ }^{3} \mathrm{P}$ & 2 & 1536 & 1.317 & $1.11 \mathrm{E}+02$ \\
\hline 6 & $4 \mathrm{~s}^{2} 4 \mathrm{p}^{21} \mathrm{~S}$ & 0 & 1613 & 0.000 & $8.75 \mathrm{E}+01$ \\
\hline 7 & $4 s 4 p^{3}\left({ }^{2} D\right){ }^{3} D$ & 1 & 1637 & 1.063 & $2.82 \mathrm{E}-03$ \\
\hline 8 & $4 s^{2} 4 p 4 d^{3} F$ & 2 & 1980 & 0.771 & $8.81 \mathrm{E}-02$ \\
\hline 9 & $4 \mathrm{~s} 24 \mathrm{p} 4 \mathrm{~d}^{3} \mathrm{D}$ & 1 & 2124 & 0.875 & $5.99 \mathrm{E}-04$ \\
\hline 10 & $4 s 4 p^{3}\left({ }^{4} S\right){ }^{5} S$ & 2 & 2159 & 1.458 & $2.42 \mathrm{E}-02$ \\
\hline 11 & $4 s^{2} 4 p 4 d^{3} F$ & 3 & 2195 & 1.181 & $1.13 \mathrm{E}-02$ \\
\hline 12 & $4 s 4 p^{3}\left({ }^{2} D\right){ }^{3} D$ & 2 & 2292 & 1.362 & $1.94 \mathrm{E}-03$ \\
\hline 13 & $4 s 4 p^{3}\left({ }^{2} D\right){ }^{3} D$ & 3 & 2328 & 1.265 & $3.49 \mathrm{E}-03$ \\
\hline 14 & $4 \mathrm{~s} 4 \mathrm{p}^{3}\left({ }^{2} \mathrm{P}\right){ }^{3} \mathrm{P}$ & 0 & 2355 & 0.000 & $3.96 \mathrm{E}-03$ \\
\hline 15 & $4 \mathrm{~s} 4 \mathrm{p}^{3}\left({ }^{2} \mathrm{P}\right){ }^{3} \mathrm{P}$ & 1 & 2410 & 1.281 & $2.22 \mathrm{E}-03$ \\
\hline 16 & $4 s 4 p^{3}\left({ }^{2} D\right){ }^{1} D$ & 2 & 2433 & 1.101 & $1.45 \mathrm{E}-03$ \\
\hline 17 & $4 s 4 p^{3}\left({ }^{4} S\right){ }^{3} S$ & 1 & 2444 & 1.364 & $1.08 \mathrm{E}-03$ \\
\hline 18 & $4 s^{2} 4 p 4 d^{3} D$ & 2 & 2847 & 1.054 & $6.67 \mathrm{E}-04$ \\
\hline 19 & $4 \mathrm{~s}^{2} 4 \mathrm{p} 4 \mathrm{~d}^{3} \mathrm{P}$ & 1 & 2857 & 1.134 & 7.74E-04 \\
\hline 20 & $4 \mathrm{~s}^{2} 4 \mathrm{p} 4 \mathrm{~d}^{3} \mathrm{P}$ & 0 & 2863 & 0.000 & $8.03 \mathrm{E}-04$ \\
\hline 21 & $4 \mathrm{~s}^{2} 4 \mathrm{p} 4 \mathrm{~d}^{3} \mathrm{~F}_{\mathrm{a}}$ & 3 & 2866 & 1.125 & $8.36 \mathrm{E}-04$ \\
\hline 22 & $4 s^{2} 4 p 4 d^{3} F$ & 4 & 2928 & 1.250 & $2.36 \mathrm{E}+02$ \\
\hline 23 & $4 \mathrm{~s}^{2} 4 \mathrm{p} 4 \mathrm{~d}^{3} \mathrm{P}$ & 2 & 2933 & 1.299 & $2.42 \mathrm{E}-02$ \\
\hline 24 & $4 s^{2} 4 p 4 d^{3} D$ & 3 & 3082 & 1.180 & $1.24 \mathrm{E}-03$ \\
\hline 25 & $4 \mathrm{~s}^{2} 4 \mathrm{p} 4 \mathrm{~d}^{1} \mathrm{P}$ & 1 & 3092 & 1.124 & $2.17 \mathrm{E}-03$ \\
\hline 26 & $4 s 4 \mathrm{p}^{3}\left({ }^{2} \mathrm{P}\right){ }^{3} \mathrm{P}_{\mathrm{a}}$ & 2 & 3175 & 1.381 & $1.17 \mathrm{E}-03$ \\
\hline \multirow[t]{2}{*}{27} & $4 \mathrm{~s} 4 \mathrm{p}^{3}\left({ }^{2} \mathrm{P}\right){ }^{1} \mathrm{P}$ & 1 & 3280 & 1.159 & $7.28 \mathrm{E}-04$ \\
\hline & $\mathrm{W}^{43+}$ & & & & \\
\hline 1 & $4 s^{2} 4 p^{2} \mathrm{P}$ & 0.5 & 0 & 0.667 & - \\
\hline 2 & $4 s 4 p^{2}{ }^{4} \mathrm{P}$ & 0.5 & 781 & 2.200 & $3.21 \mathrm{E}-02$ \\
\hline 3 & $4 s^{2} 4 p^{2} \mathrm{P}$ & 1.5 & 791 & 1.333 & $2.13 \mathrm{E}+02$ \\
\hline 4 & $4 \mathrm{~s} 4 \mathrm{p}^{24} \mathrm{P}$ & 1.5 & 1465 & 1.663 & 1.97E-01 \\
\hline 5 & $4 s 4 p^{22} \mathrm{D}$ & 2.5 & 1533 & 1.365 & $6.47 \mathrm{E}-02$ \\
\hline 6 & $4 s 4 p^{22} D$ & 1.5 & 1632 & 0.980 & $2.71 \mathrm{E}-03$ \\
\hline 7 & $4 \mathrm{~s} 4 \mathrm{p}^{22} \mathrm{P}$ & 0.5 & 1652 & 1.235 & $1.41 \mathrm{E}-03$ \\
\hline 8 & $4 \mathrm{~s}^{2} 4 \mathrm{~d}^{2} \mathrm{D}$ & 1.5 & 2085 & 0.827 & $8.12 \mathrm{E}-04$ \\
\hline 9 & $4 s^{2} 4 d^{2} D$ & 2.5 & 2203 & 1.301 & $1.14 \mathrm{E}-02$ \\
\hline 10 & $4 s 4 p^{24} \mathrm{P}$ & 2.5 & 2346 & 1.335 & $1.96 \mathrm{E}-03$ \\
\hline 11 & $4 s 4 p^{22} S$ & 0.5 & 2442 & 1.898 & $2.01 \mathrm{E}-03$ \\
\hline 12 & $4 \mathrm{~s} 4 \mathrm{p}^{22} \mathrm{P}$ & 1.5 & 2472 & 1.197 & $9.60 \mathrm{E}-04$ \\
\hline
\end{tabular}

In addition to the level energies $E$, Table 1 lists other important energy level properties, such as Landé $g$-factors and radiative lifetimes $\tau$. The Landé $g$-factor is a dimensionless parameter which describes the fine-structure level splitting in a magnetic field. The knowledge of these factors is important while studying tungsten ions in fusion plasma where magnetic fields are extremely 
strong. In the case of multiconfiguration eigenfunctions, the Landé $g$-factor for any level $K$ with the total angular momentum $J$ is given by

$$
\begin{aligned}
& g_{K}=\sum_{C L S} a_{K}^{2}(C L S J) \\
& \left(1+\frac{J(J+1)-L(L+1)+S(S+1)}{2 J(J+1)}\right) .
\end{aligned}
$$

Here $a_{K}(C L S J)$ stands for the CI wavefunction expansion coefficient. The summation runs over all expansion terms of the eigenfunction, i.e. over all configurations and their intermediate momenta $(C)$, the total spin $(S)$, and orbital $(L)$ momenta.

Total radiative lifetimes $\tau$ are determined by the sum of all radiative emission transition probabilities (rates) $A$ from the excited level to all levels having lower energies:

$$
\tau=\left(\sum_{\mathrm{f}<\mathrm{i}} A_{\text {if }}\right)^{-1} .
$$

The total radiative lifetimes $\tau$ are discussed in the next section.

We used original computer codes when implementing our QR approach for the data production along with the codes [28-30] which were adopted for our calculation needs.

\section{Results and discussion}

We investigate the three lowest configurations $4 \mathrm{~s}^{2} 4 \mathrm{p}^{N}, 4 \mathrm{~s}^{2} 4 \mathrm{p}^{N-1} 4 \mathrm{~d}$ and $4 \mathrm{~s} 4 \mathrm{p}^{N+1}$ of the tungsten ions $\mathrm{W}^{38+}-\mathrm{W}^{43+}$ by using the $\mathrm{QR}$ approach. The calculated level energies, their radiative lifetimes $\tau$, and other spectroscopic parameters of the levels are presented in Table 1. Meanwhile, a comprehensive comparison with available experimental data and with level energies determined using other theoretical methods was performed and the accuracy assessment was given elsewhere [13].

\subsection{Transition wavelengths}

The highly-charged tungsten ions were previously investigated in [10]. That work tabulates the measured wavelengths of the E1 and M1 transitions, most of them being transitions to the ground lev$\mathrm{el}$, and the calculated data obtained in a relativistic parametric potential (RPP) method implemented in the HULLAC [32] package. Table 2 contains the experimental and calculated wavelengths of the E1 transitions from [10] and the QR wavelengths calculated in the present work for the ions $\mathrm{W}^{38+}-\mathrm{W}^{43+}$.

The wavelengths are determined experimentally only for two $\mathrm{E} 1$ transitions in $\mathrm{W}^{38+}$. For the first line, $\lambda_{\exp }=46.40 \AA$, the agreement between the experimental and calculated values is very similar for both the QR and RPP methods. Meanwhile, the discrepancy between the experimental wavelength and the value of $\lambda_{\mathrm{MCDHF}}=46.45 \AA$ from [20] is even smaller. For another transition at $\lambda_{\exp }=63.68 \AA$, the agreement of the QR result $\lambda_{\mathrm{QR}}=63.57 \AA$ with the experimental value is excellent, but the value $\lambda_{\mathrm{MCDHF}}=63.64 \AA$ from [20] is even closer. The deviation of the RPP wavelength from the experimental data is noticeably worse. For the ion $\mathrm{W}^{39+}$, the QR results are closer to the experimental ones than the calculated data from [10]. For the ion $\mathrm{W}^{40+}$, the deviation of the calculated data from the experimental wavelengths is slightly larger for the transition with $\lambda_{\text {exp }}=65.81 \AA$. The agreement between the QR wavelength and the experimental data is excellent for other transition at $\lambda_{\exp }=62.60 \AA$ in $\mathrm{W}^{40+}$. A wide emission band is registered at $46.88 \AA$ in the spectrum of this ion. Five transition lines defined in [10] are identified as making a contribution to this wide line. Unfortunately, this identification for us looks uncertain. Thus we cannot assign particular QR transitions to this band beyond doubt. (The transitions which can possibly contribute to this band are listed later in Table 6.)

For the ion $\mathrm{W}^{41+}$, our QR results differ from the experimental wavelengths more noticeably compared to the data from [10] - although these differences are not so significant. For the ions $\mathrm{W}^{42+}$ and $\mathrm{W}^{43+}$, the $\mathrm{QR}$ wavelengths are very close to the experimental values. The averaged deviations are significantly smaller compared to the deviations of the RPP data from [10].

The work [10] also presents several experimental wavelengths for the M1 transitions in the ions $\mathrm{W}^{38+}$ and $\mathrm{W}^{39+}$. These transitions are also presented in Table 2 along with the QR results. The transitions in the ion $\mathrm{W}^{38+}$ are identified as M1 transitions among the levels of the excited configuration $4 s^{2} 4 \mathrm{p}^{5} 4 \mathrm{~d}$. The difference between our QR results and the experimental wavelengths is 
Table 2. Comparison of the transition wavelengths $\lambda$ (in $\AA$ ) calculated in this work (QR) with data from [10].

\begin{tabular}{|c|c|c|c|c|c|}
\hline Ion & Initial level & Final level & QR & $\exp [10]$ & $\mathrm{RPP}$ [10] \\
\hline \multirow[t]{5}{*}{$W^{38+}$} & $4 \mathrm{~s}^{2} 4 \mathrm{p}^{5} 4 \mathrm{~d}^{1} \mathrm{P}_{1}$ & $4 s^{2} 4 p^{61} S_{0}$ & 46.77 & 46.40 & 46.064 \\
\hline & $4 s^{2} 4 p^{5} 4 d^{3} D_{1}$ & $4 s^{2} 4 p^{6} S_{0}$ & 63.57 & 63.68 & 63.249 \\
\hline & $4 s^{2} 4 p^{5} 4 d^{3} D_{3}$ & $4 s^{2} 4 p^{5} 4 d^{3} F_{3}$ & 565.73 & 532.87 & 523.67 \\
\hline & $4 s^{2} 4 p^{5} 4 d^{3} D_{3}$ & $4 s^{2} 4 p^{5} 4 d^{3} D_{2}$ & 594.36 & 559.04 & 556.759 \\
\hline & $4 \mathrm{~s}^{2} 4 \mathrm{p}^{5} 4 \mathrm{~d}^{3} \mathrm{~F}_{4}$ & $4 \mathrm{~s}^{2} 4 \mathrm{p}^{5} 4 \mathrm{~d}^{3} \mathrm{~F}_{3}$ & 881.71 & 799.23 & 798.080 \\
\hline \multirow[t]{8}{*}{$\mathrm{W}^{39+}$} & $4 \mathrm{~s}^{2} 4 \mathrm{p}^{4}\left({ }^{3} \mathrm{P}\right) 4 \mathrm{~d}^{2} \mathrm{P}_{3 / 2}$ & $4 s^{2} 4 p^{52} \mathrm{P}_{3 / 2}$ & 46.86 & 46.81 & 46.712 \\
\hline & $4 \mathrm{~s}^{2} 4 \mathrm{p}^{4}\left({ }^{3} \mathrm{P}\right) 4 \mathrm{~d}^{2} \mathrm{D}_{5 / 2}^{\mathrm{a}}$ & $4 s^{2} 4 p^{52} P_{3 / 2}$ & 46.91 & 46.81 & 46.119 \\
\hline & $4 \mathrm{~s}^{2} 4 \mathrm{p}^{4}\left({ }^{1} \mathrm{D}\right) 4 \mathrm{~d}^{2} \mathrm{P}_{3 / 2}$ & $4 s^{2} 4 p^{52} P_{3 / 2}$ & 47.25 & 46.81 & 46.124 \\
\hline & $4 \mathrm{~s}^{2} 4 \mathrm{p}^{4}\left({ }^{3} \mathrm{P}\right) 4 \mathrm{~d}^{2} \mathrm{D}_{5 / 2}$ & $4 \mathrm{~s}^{2} 4 \mathrm{p}^{5} \mathrm{P}_{3 / 2}$ & 64.35 & 64.74 & 63.798 \\
\hline & $4 \mathrm{~s}^{2} 4 \mathrm{p}^{4}\left({ }^{3} \mathrm{P}\right) 4 \mathrm{~d}^{4} \mathrm{P}_{3 / 2}$ & $4 \mathrm{~s}^{2} 4 \mathrm{p}^{5} \mathrm{P}_{3 / 2}$ & 65.42 & 65.76 & 64.851 \\
\hline & $4 s^{2} 4 p^{52} P_{1 / 2}$ & $4 \mathrm{~s}^{2} 4 \mathrm{p}^{5} \mathrm{P}_{3 / 2}$ & 133.67 & 131.8 & 133.609 \\
\hline & $4 \mathrm{~s}^{2} 4 \mathrm{p}^{4}\left({ }^{3} \mathrm{P}\right) 4 \mathrm{~d}^{4} \mathrm{D}_{7 / 2}$ & $4 s^{2} 4 \mathrm{p}^{4}\left({ }^{3} \mathrm{P}\right) 4 \mathrm{~d}^{4} \mathrm{D}_{5 / 2}$ & 730.34 & 698.37 & 687.875 \\
\hline & $4 s^{2} 4 p^{4}\left({ }^{3} \mathrm{P}\right) 4 d^{4} \mathrm{~F}_{9 / 2}$ & $4 \mathrm{~s}^{2} 4 \mathrm{p}^{4}\left({ }^{3} \mathrm{P}\right) 4 \mathrm{~d}^{4} \mathrm{~F}_{7 / 2}$ & 802.47 & 774.76 & 759.439 \\
\hline \multirow[t]{2}{*}{$\mathrm{W}^{40+}$} & $4 s 4 p^{5}{ }^{3} P_{2}$ & $4 \mathrm{~s}^{2} 4 \mathrm{p}^{4} \mathrm{P}_{2}$ & 62.64 & 62.60 & 62.337 \\
\hline & $4 \mathrm{~s}^{2} 4 \mathrm{p}^{3}\left({ }^{2} \mathrm{P}\right) 4 \mathrm{~d}^{3} \mathrm{D}_{3}$ & $4 s^{2} 4 p^{4} P_{2}$ & 64.68 & 65.81 & 64.791 \\
\hline \multirow[t]{3}{*}{$\mathrm{W}^{41+}$} & $4 s 4 p^{42} S_{1 / 2}$ & $4 s^{2} 4 p^{32} P_{3 / 2}$ & 61.24 & 60.71 & 60.226 \\
\hline & $4 s 4 p^{44} P_{5 / 2}$ & $4 s^{2} 4 p^{32} P_{3 / 2}$ & 64.60 & 64.82 & 64.689 \\
\hline & $4 s 4 p^{4}{ }^{4} P_{5 / 2}$ & $4 s^{2} 4 p^{32} P_{3 / 2}$ & 69.74 & 70.15 & 69.963 \\
\hline \multirow[t]{2}{*}{$\mathrm{W}^{42+}$} & $4 s^{2} 4 p 4 d^{3} D_{1}$ & $4 \mathrm{~s}^{2} 4 \mathrm{p}^{23} \mathrm{P}_{0}$ & 47.09 & 46.97 & 46.724 \\
\hline & $4 \mathrm{~s} 4 \mathrm{p}^{33} \mathrm{D}_{1}$ & $4 \mathrm{~s}^{2} 4 \mathrm{p}^{23} \mathrm{P}_{0}$ & 61.08 & 61.30 & 60.707 \\
\hline \multirow[t]{3}{*}{$\mathrm{W}^{43+}$} & $4 \mathrm{~s} 4 \mathrm{p}^{22} \mathrm{P}_{3 / 2}$ & $4 s^{2} 4 \mathrm{p}^{2} \mathrm{P}_{1 / 2}$ & 47.97 & 47.69 & 47.576 \\
\hline & $4 s 4 p^{22} D_{1 / 2}$ & $4 \mathrm{~s}^{2} 4 \mathrm{p}^{2} \mathrm{P}_{1 / 2}$ & 60.55 & 60.61 & 59.883 \\
\hline & $4 s 4 p^{22} S_{3 / 2}$ & $4 s^{2} 4 p^{2} P_{1 / 2}$ & 61.28 & 61.29 & 60.865 \\
\hline
\end{tabular}

approximately $6 \%$ for the transitions at $\lambda_{\text {exp }}=532.87 \AA$ and $\lambda_{\text {exp }}=559.04 \AA$, and approximately $10 \%$ for the transition at $\lambda_{\exp }=799.23 \AA$. For these lines, the agreement between the RPP results and the experimental data is significantly better than that between the QR results and the experimental ones.

For the ion $\mathrm{W}^{39+}$, the agreement of the RPP wavelengths with the experimental data is also better than the agreement of the QR results for three transitions among the levels of the excited configurations. Nevertheless, the difference between the $\mathrm{QR}$ wavelengths and experimental ones is smaller than in the case of $\mathrm{W}^{38+}$. The line at $131.8 \AA$ originates from the transition between the levels of the ground configuration of $\mathrm{W}^{39+}$. Here the agreement with the experimental wavelength is approximately $1.4 \%$ both for the QR and RPP data.

The experimentally measured M1 transitions for other ions considered in the current study are not available. Only the RPP calculation results are presented in [10]. In general, the QR results are in a good agreement with the experimental wavelengths from [10].

\subsection{Transition probabilities}

Table 3 contains the calculated data for transitions among the levels of the ground configuration 
Table 3. Comparison of the transition wavelengths $\lambda$ and transition probabilities $A$ calculated in this work (QR) with the MCDF results from [15].

\begin{tabular}{|c|c|c|c|c|c|c|c|}
\hline & & & & \multicolumn{2}{|c|}{$\lambda(\AA)$} & \multicolumn{2}{|c|}{$A, \mathrm{~s}^{-1}$} \\
\hline Ion & Initial level & Final level & Type & QR & MCDF & QR & MCDF \\
\hline $\mathrm{W}^{39+}$ & $4 s^{2} 4 p^{52} P_{1 / 2}$ & $4 s^{2} 4 p^{52} P_{3 / 2}$ & $\mathrm{M} 1+\mathrm{E} 2$ & 133.67 & 133.82 & $7.86 \mathrm{E}+6$ & $7.65 \mathrm{E}+6$ \\
\hline \multirow[t]{7}{*}{$\mathrm{W}^{40+}$} & $4 s^{2} 4 p^{43} P_{0}$ & $4 s^{2} 4 p^{43} P_{2}$ & $\mathrm{E} 2$ & 64.69 & 64.59 & $7.10 \mathrm{E}+3$ & $1.96 \mathrm{E}+4$ \\
\hline & $4 s^{2} 4 p^{43} P_{0}$ & $4 s^{2} 4 p^{43} P_{1}$ & M1 & 124.64 & 123.85 & $1.73 \mathrm{E}+7$ & $1.72 \mathrm{E}+7$ \\
\hline & $4 s^{2} 4 p^{4}{ }^{1} D_{2}$ & $4 s^{2} 4 p^{43} P_{2}$ & $\mathrm{M} 1+\mathrm{E} 2$ & 128.69 & 128.53 & $4.26 \mathrm{E}+6$ & $4.18 \mathrm{E}+6$ \\
\hline & $4 s^{2} 4 p^{43} P_{0}$ & $4 s^{2} 4 p^{41} D_{2}$ & E2 & 130.07 & 129.84 & $8.60 \mathrm{E}+5$ & $8.23 \mathrm{E}+5$ \\
\hline & $4 s^{2} 4 p^{43} P_{1}$ & $4 s^{2} 4 p^{43} P_{2}$ & $\mathrm{M} 1+\mathrm{E} 2$ & 134.49 & 135.00 & $6.59 \mathrm{E}+6$ & $6.39 \mathrm{E}+6$ \\
\hline & $4 s^{2} 4 p^{41} D_{2}$ & $4 s^{2} 4 p^{4}{ }^{1} S_{0}$ & E2 & 142.23 & 141.89 & $5.08 \mathrm{E}+4$ & $4.44 \mathrm{E}+4$ \\
\hline & $4 s^{2} 4 p^{43} P_{1}$ & $4 s^{2} 4 p^{4}{ }^{1} S_{0}$ & M1 & 149.34 & 149.82 & $2.02 \mathrm{E}+6$ & $1.97 \mathrm{E}+6$ \\
\hline \multirow[t]{6}{*}{$\mathrm{W}^{41+}$} & $4 s^{2} 4 p^{32} P_{3 / 2}$ & $4 s^{2} 4 p^{3}{ }^{4} S_{3 / 2}$ & $\mathrm{M} 1+\mathrm{E} 2$ & 121.35 & 120.98 & $9.18 E+6$ & $9.17 \mathrm{E}+6$ \\
\hline & $4 \mathrm{~s}^{2} 4 \mathrm{p}^{32} \mathrm{P}_{1 / 2}$ & $4 \mathrm{~s}^{2} 4 \mathrm{p}^{32} \mathrm{P}_{3 / 2}$ & $\mathrm{M} 1+\mathrm{E} 2$ & 122.33 & 122.14 & $4.82 \mathrm{E}+6$ & $9.17 \mathrm{E}+6$ \\
\hline & $4 s^{2} 4 p^{32} P_{3 / 2}$ & $4 s^{2} 4 p^{32} D_{5 / 2}$ & $\mathrm{M} 1+\mathrm{E} 2$ & 128.44 & 127.99 & $2.64 \mathrm{E}+6$ & $2.60 \mathrm{E}+6$ \\
\hline & $4 s^{2} 4 \mathrm{p}^{32} \mathrm{D}_{5 / 2}$ & $4 \mathrm{~s}^{2} 4 \mathrm{p}^{32} \mathrm{P}_{3 / 2}$ & $\mathrm{M} 1+\mathrm{E} 2$ & 131.69 & 131.35 & $1.49 \mathrm{E}+6$ & $1.47 \mathrm{E}+6$ \\
\hline & $4 s^{2} 4 p^{32} P_{3 / 2}$ & $4 s^{2} 4 p^{32} P_{1 / 2}$ & $\mathrm{M} 1+\mathrm{E} 2$ & 138.80 & 138.14 & $1.77 \mathrm{E}+6$ & $1.83 \mathrm{E}+6$ \\
\hline & $4 s^{2} 4 p^{34} S_{3 / 2}$ & $4 s^{2} 4 p^{32} P_{3 / 2}$ & $\mathrm{M} 1+\mathrm{E} 2$ & 140.09 & 139.66 & $7.11 \mathrm{E}+6$ & $7.05 \mathrm{E}+6$ \\
\hline \multirow[t]{6}{*}{$\mathrm{W}^{42+}$} & $4 s^{2} 4 p^{21} S_{0}$ & $4 s^{2} 4 \mathrm{p}^{23} \mathrm{P}_{1}$ & M1 & 113.72 & 114.13 & $1.08 \mathrm{E}+7$ & $1.04 \mathrm{E}+6$ \\
\hline & $4 s^{2} 4 p^{21} S_{0}$ & $4 s^{2} 4 p^{21} D_{2}$ & E2 & 118.94 & 118.96 & $6.24 \mathrm{E}+5$ & $6.58 \mathrm{E}+5$ \\
\hline & $4 s^{2} 4 p^{23} P_{2}$ & $4 s^{2} 4 p^{23} P_{1}$ & $\mathrm{M} 1+\mathrm{E} 2$ & 124.55 & 125.22 & $4.56 \mathrm{E}+6$ & $4.37 \mathrm{E}+6$ \\
\hline & $4 s^{2} 4 p^{21} D_{2}$ & $4 \mathrm{~s}^{2} 4 \mathrm{p}^{23} \mathrm{P}_{0}$ & E2 & 129.50 & 129.58 & $1.55 \mathrm{E}+5$ & $1.48 \mathrm{E}+5$ \\
\hline & $4 s^{2} 4 p^{23} P_{2}$ & $4 s^{2} 4 p^{21} D_{2}$ & $\mathrm{M} 1+\mathrm{E} 2$ & 130.85 & 131.06 & $4.47 \mathrm{E}+6$ & $4.34 \mathrm{E}+6$ \\
\hline & $4 s^{2} 4 p^{23} P_{1}$ & $4 s^{2} 4 \mathrm{p}^{23} \mathrm{P}_{0}$ & M1 & 136.32 & 135.85 & $5.00 \mathrm{E}+6$ & $4.93 \mathrm{E}+6$ \\
\hline $\mathrm{W}^{43+}$ & $4 s^{2} 4 p^{2} P_{3 / 2}$ & $4 s^{2} 4 \mathrm{p}^{2} \mathrm{P}_{1 / 2}$ & $\mathrm{M} 1+\mathrm{E} 2$ & 126.35 & 126.47 & $4.69 \mathrm{E}+6$ & $4.55 \mathrm{E}+6$ \\
\hline
\end{tabular}

determined in the QR approach and those calculated in the multiconfigurational Dirac-Fock approximation (MCDF) [15]. As the total transition probabilities arising both from the M1 and E2 radiative transitions are presented in [15], we also tabulate the QR data in this way. Meanwhile, separate QR transition probabilities for each type of transition are listed in Tables 4-9.

It is worth noting here that in most cases for the same pair of levels, where both the E2 and the M1 transitions are allowed, the $A$ values of the E2 transitions are only up to 20 times smaller than those of the M1 transitions. For the ion $\mathrm{W}^{41+}$, the E2 transition probability for the line $\lambda_{\mathrm{QR}}=131.69 \AA$ is just some 5 times smaller compared to that of the M1 transition for this line (see
Table 7). Consequently, after the E2 transition is included into the calculation of the radiative lifetime $\tau$, its value is reduced by some $15 \%$.

In general, the accuracy of transition data calculated in the QR and MCDF approximations is very similar. For all transitions presented in $\mathrm{Ta}$ ble 3, the difference between the QR and MCDF transition wavelengths is less than $1 \%$. The difference between the transition probabilities $A$ is just few percent. Only the weak E2 transitions $\left(\lambda_{\mathrm{QR}}=64.69 \AA\right.$ and $\lambda_{\mathrm{QR}}=142.23 \AA$ ) in the ion $\mathrm{W}^{40+}$ stand out. Although their transition wavelengths $\lambda$ calculated by the QR and by MCDF approximations are very close (like for other investigated transitions), the transition probability values $A$ differ significantly. Meanwhile, the QR and MCDF 
results for the weak E2 transitions in the ion $\mathrm{W}^{42+}$ agree quite well.

The radiative lifetimes $\tau$ of the excited levels in the current work are determined by utilizing the calculated transition probabilities $A$ of the E1, $\mathrm{M} 2$ and $\mathrm{E} 3$ radiative transitions among the levels of different-parity configurations and those of the M1 and E2 transitions among the levels of the sameparity configurations. The transition probabilities $A$ and other spectroscopic parameters are presented in Tables 4-9. These tables contain emission transitions from each excited level, sorted in a transition probability descending order. The weakest presented transition is only up to 100 times weaker than the strongest one from any particular level. Here we must underline that all calculated radiative transi- tion probabilities $A$ are included into the lifetime $\tau$ calculations whereas the data sets presented in $\mathrm{Ta}-$ bles 4-9 are more limited.

\subsection{Uncertainties of transition data}

The uncertainty of transition probability is caused by two factors. First of all, the uncertainty is caused by the uncertainty of the transition operator matrix element due to the inaccuracy of the level eigenfunction. The quality and reliability of this eigenfunction can be determined by performing several calculations on different CI bases and checking the convergence of the transition line strength $S$ (or the square of the transition operator matrix element), which does not depend

Table 4. Radiative transition wavelengths $\lambda$, transition probabilities $A$, their relative uncertainties $u_{\lambda}$ and $u_{A}$ (in \%) for the $\mathrm{W}^{38+}$ ion.

\begin{tabular}{|c|c|c|c|c|c|c|c|c|}
\hline$K_{\mathrm{i}}$ & $J_{\mathrm{i}}$ & $K_{\mathrm{f}}$ & $J_{\mathrm{f}}$ & Type & $\lambda(\AA)$ & $u_{\lambda}$ & $A\left(\mathrm{~s}^{-1}\right)$ & $u_{A}$ \\
\hline 3 & 1 & 1 & 0 & E1 & 80.07 & 0.4 & $2.23 \mathrm{E}+09$ & 1.1 \\
\hline 4 & 3 & 1 & 0 & E3 & 78.39 & 0.4 & $2.19 \mathrm{E}+01$ & 2.6 \\
\hline \multirow[t]{3}{*}{5} & 2 & 3 & 1 & M1 & 2827 & 18.8 & $3.85 \mathrm{E}+02$ & 57.0 \\
\hline & & 1 & 0 & M2 & 77.87 & 0.4 & $1.14 \mathrm{E}+02$ & 1.8 \\
\hline & & 4 & 3 & M1 & 11746 & 78.1 & $5.68 \mathrm{E}+00$ & 281.8 \\
\hline \multirow[t]{2}{*}{6} & 4 & 4 & 3 & M1 & 881.7 & 5.9 & $1.70 \mathrm{E}+04$ & 17.6 \\
\hline & & 4 & 3 & E2 & 881.7 & 5.9 & $3.51 \mathrm{E}+00$ & 29.5 \\
\hline \multirow[t]{4}{*}{7} & 2 & 3 & 1 & M1 & 630.1 & 4.2 & $2.55 \mathrm{E}+04$ & 12.6 \\
\hline & & 1 & 0 & M2 & 71.05 & 0.3 & $1.37 \mathrm{E}+04$ & 1.7 \\
\hline & & 5 & 2 & M1 & 810.7 & 5.4 & $9.50 \mathrm{E}+03$ & 16.2 \\
\hline & & 4 & 3 & M1 & 758.4 & 5.0 & $1.74 \mathrm{E}+03$ & 15.1 \\
\hline \multirow[t]{2}{*}{8} & 3 & 5 & 2 & M1 & 594.4 & 4.0 & $3.75 \mathrm{E}+04$ & 11.9 \\
\hline & & 4 & 3 & M1 & 565.7 & 3.8 & $1.31 \mathrm{E}+04$ & 11.3 \\
\hline 9 & 1 & 1 & 0 & E1 & 63.57 & 0.3 & $6.06 \mathrm{E}+11$ & 0.9 \\
\hline \multirow[t]{3}{*}{10} & 2 & 4 & 3 & M1 & 141.4 & 0.9 & $4.54 \mathrm{E}+06$ & 2.8 \\
\hline & & 5 & 2 & M1 & 143.1 & 1.0 & $1.59 \mathrm{E}+06$ & 2.9 \\
\hline & & 3 & 1 & M1 & 136.2 & 0.9 & $3.10 \mathrm{E}+05$ & 2.7 \\
\hline \multirow[t]{5}{*}{11} & 2 & 7 & 2 & M1 & 138.4 & 0.9 & $2.65 \mathrm{E}+06$ & 2.8 \\
\hline & & 8 & 3 & M1 & 147.6 & 1.0 & $1.93 \mathrm{E}+06$ & 2.9 \\
\hline & & 9 & 1 & M1 & 179.5 & 1.2 & $1.54 \mathrm{E}+06$ & 3.6 \\
\hline & & 6 & 4 & E2 & 135.0 & 0.9 & $2.05 \mathrm{E}+05$ & 4.5 \\
\hline & & 3 & 1 & M1 & 113.5 & 0.8 & $1.77 \mathrm{E}+05$ & 2.3 \\
\hline 12 & 1 & 1 & 0 & E1 & 46.77 & 0.2 & $2.14 \mathrm{E}+12$ & 0.7 \\
\hline \multirow[t]{3}{*}{13} & 3 & 6 & 4 & M1 & 131.1 & 0.9 & $4.71 \mathrm{E}+06$ & 2.6 \\
\hline & & 8 & 3 & M1 & 143.0 & 1.0 & $1.79 \mathrm{E}+06$ & 2.9 \\
\hline & & 7 & 2 & M1 & 134.4 & 0.9 & $5.70 \mathrm{E}+05$ & 2.7 \\
\hline
\end{tabular}


Table 5. Radiative transition wavelengths $\lambda$, transition probabilities $A$, their relative uncertainties $u_{\lambda}$ and $u_{A}$ (in \%) for the $\mathrm{W}^{39+}$ ion.

\begin{tabular}{|c|c|c|c|c|c|c|c|c|}
\hline$K_{\mathrm{i}}$ & $J_{\mathrm{i}}$ & $K_{\mathrm{f}}$ & $J_{\mathrm{f}}$ & Type & $\lambda(\AA)$ & $u_{\lambda}$ & $A\left(\mathrm{~s}^{-1}\right)$ & $u_{A}$ \\
\hline \multirow[t]{2}{*}{2} & $1 / 2$ & 1 & $3 / 2$ & M1 & 133.7 & 0.9 & $7.51 \mathrm{E}+06$ & 2.6 \\
\hline & & 1 & $3 / 2$ & E2 & 133.7 & 0.9 & $3.54 \mathrm{E}+05$ & 4.4 \\
\hline 3 & $3 / 2$ & 1 & $3 / 2$ & E1 & 81.82 & 0.5 & $2.54 \mathrm{E}+09$ & 1.6 \\
\hline 4 & $1 / 2$ & 1 & $3 / 2$ & E1 & 80.71 & 0.5 & $1.08 \mathrm{E}+10$ & 1.6 \\
\hline 5 & $5 / 2$ & 1 & $3 / 2$ & E1 & 80.63 & 0.5 & $1.27 \mathrm{E}+09$ & 1.6 \\
\hline 6 & $7 / 2$ & 1 & $3 / 2$ & M2 & 79.20 & 0.5 & $1.52 \mathrm{E}+02$ & 2.6 \\
\hline 7 & $3 / 2$ & 1 & $3 / 2$ & E1 & 75.31 & 0.5 & $2.03 \mathrm{E}+08$ & 1.5 \\
\hline \multirow[t]{2}{*}{8} & $1 / 2$ & 1 & $3 / 2$ & E1 & 72.65 & 0.5 & $2.48 \mathrm{E}+09$ & 1.4 \\
\hline & & 2 & $1 / 2$ & E1 & 159.1 & 1.5 & $1.66 \mathrm{E}+09$ & 4.5 \\
\hline \multirow[t]{3}{*}{9} & $7 / 2$ & 5 & $5 / 2$ & M1 & 730.3 & 6.8 & $2.03 \mathrm{E}+04$ & 20.5 \\
\hline & & 1 & $3 / 2$ & M2 & 72.61 & 0.5 & $1.07 \mathrm{E}+04$ & 2.4 \\
\hline & & 6 & $7 / 2$ & M1 & 872.6 & 8.1 & $6.62 \mathrm{E}+03$ & 24.5 \\
\hline 10 & $9 / 2$ & 6 & $7 / 2$ & M1 & 802.5 & 7.5 & $2.28 \mathrm{E}+04$ & 22.5 \\
\hline 11 & $5 / 2$ & 1 & $3 / 2$ & E1 & 67.07 & 0.4 & $1.05 \mathrm{E}+06$ & 1.3 \\
\hline 12 & $3 / 2$ & 1 & $3 / 2$ & E1 & 65.42 & 0.4 & $3.94 \mathrm{E}+11$ & 1.3 \\
\hline 13 & $5 / 2$ & 1 & $3 / 2$ & E1 & 64.35 & 0.4 & $5.45 \mathrm{E}+11$ & 1.3 \\
\hline \multirow[t]{2}{*}{14} & $1 / 2$ & 1 & $3 / 2$ & E1 & 61.58 & 0.4 & $6.02 \mathrm{E}+11$ & 1.2 \\
\hline & & 2 & $1 / 2$ & E1 & 114.2 & 1.1 & $2.58 \mathrm{E}+10$ & 3.2 \\
\hline \multirow[t]{2}{*}{15} & $1 / 2$ & 1 & $3 / 2$ & E1 & 52.20 & 0.5 & $6.55 \mathrm{E}+09$ & 1.5 \\
\hline & & 2 & $1 / 2$ & E1 & 85.65 & 1.0 & $1.82 \mathrm{E}+09$ & 3.0 \\
\hline \multirow[t]{2}{*}{16} & $3 / 2$ & 2 & $1 / 2$ & E1 & 82.92 & 1.0 & $1.66 \mathrm{E}+09$ & 2.9 \\
\hline & & 1 & $3 / 2$ & E1 & 51.17 & 0.5 & $1.13 \mathrm{E}+08$ & 1.5 \\
\hline 17 & $5 / 2$ & 1 & $3 / 2$ & E1 & 50.27 & 0.5 & $4.26 \mathrm{E}+10$ & 1.5 \\
\hline \multirow[t]{3}{*}{18} & $7 / 2$ & 6 & $7 / 2$ & M1 & 135.9 & 1.6 & $2.94 \mathrm{E}+06$ & 4.9 \\
\hline & & 5 & $5 / 2$ & M1 & 131.9 & 1.6 & $4.78 \mathrm{E}+05$ & 4.7 \\
\hline & & 6 & $7 / 2$ & E2 & 135.9 & 1.6 & $1.31 \mathrm{E}+05$ & 8.1 \\
\hline \multirow[t]{6}{*}{19} & $7 / 2$ & 10 & $9 / 2$ & M1 & 142.4 & 1.8 & $2.83 \mathrm{E}+06$ & 5.3 \\
\hline & & 9 & $7 / 2$ & M1 & 140.4 & 1.7 & $2.04 \mathrm{E}+06$ & 5.2 \\
\hline & & 13 & $5 / 2$ & M1 & 186.7 & 2.3 & $1.33 \mathrm{E}+06$ & 6.9 \\
\hline & & 11 & $5 / 2$ & M1 & 167.1 & 2.1 & $5.11 \mathrm{E}+05$ & 6.2 \\
\hline & & 5 & $5 / 2$ & M1 & 117.7 & 1.5 & $1.31 \mathrm{E}+05$ & 4.4 \\
\hline & & 10 & $9 / 2$ & E2 & 142.4 & 1.8 & $1.01 \mathrm{E}+05$ & 8.8 \\
\hline 20 & $3 / 2$ & 1 & $3 / 2$ & E1 & 47.25 & 0.5 & $3.60 \mathrm{E}+11$ & 1.5 \\
\hline 21 & $1 / 2$ & 1 & $3 / 2$ & E1 & 47.03 & 0.5 & $2.37 \mathrm{E}+12$ & 1.5 \\
\hline
\end{tabular}


Table 5. (continued)

\begin{tabular}{cccccccccccc}
\hline$K_{\mathrm{i}}$ & $J_{\mathrm{i}}$ & $K_{\mathrm{f}}$ & $J_{\mathrm{f}}$ & Type & $\lambda(\AA)$ & $u_{\lambda}$ & $A\left(\mathrm{~s}^{-1}\right)$ & $u_{A}$ \\
\hline 22 & $5 / 2$ & 1 & $3 / 2$ & $\mathrm{E} 1$ & 46.91 & 0.5 & $1.86 \mathrm{E}+12$ & 1.5 \\
\hline 23 & $3 / 2$ & 1 & $3 / 2$ & $\mathrm{E} 1$ & 46.86 & 0.5 & $1.38 \mathrm{E}+12$ & 1.5 \\
\hline 24 & $5 / 2$ & 1 & $3 / 2$ & $\mathrm{E} 1$ & 46.78 & 0.5 & $8.33 \mathrm{E}+07$ & 1.5 \\
\hline & & 9 & $7 / 2$ & $\mathrm{M} 1$ & 131.5 & 1.7 & $4.67 \mathrm{E}+06$ & 5.0 \\
\hline & & 11 & $5 / 2$ & $\mathrm{M} 1$ & 154.7 & 1.0 & $2.15 \mathrm{E}+06$ & 3.1 \\
\hline 25 & $9 / 2$ & 10 & $9 / 2$ & $\mathrm{M} 1$ & 132.7 & 1.7 & $2.98 \mathrm{E}+06$ & 5.0 \\
\hline & & 9 & $7 / 2$ & $\mathrm{M} 1$ & 131.0 & 1.6 & $6.84 \mathrm{E}+05$ & 4.9 \\
\hline & & 10 & $9 / 2$ & $\mathrm{E} 2$ & 132.7 & 1.7 & $1.30 \mathrm{E}+05$ & 8.3 \\
\hline 26 & $5 / 2$ & 1 & $3 / 2$ & $\mathrm{E} 1$ & 46.19 & 0.5 & $1.07 \mathrm{E}+11$ & 1.5 \\
\hline 27 & $7 / 2$ & 10 & $9 / 2$ & $\mathrm{M} 1$ & 123.5 & 1.6 & $2.61 \mathrm{E}+06$ & 4.7 \\
\hline & & 9 & $7 / 2$ & $\mathrm{M} 1$ & 122.0 & 1.6 & $8.36 \mathrm{E}+05$ & 4.7 \\
\hline & & 11 & $5 / 2$ & $\mathrm{M} 1$ & 141.7 & 1.8 & $6.65 \mathrm{E}+05$ & 5.4 \\
\hline & & 13 & $5 / 2$ & $\mathrm{M} 1$ & 155.5 & 2.0 & $2.26 \mathrm{E}+05$ & 6.0 \\
\hline 28 & $3 / 2$ & 2 & $1 / 2$ & $\mathrm{E} 1$ & 63.92 & 0.9 & $6.65 \mathrm{E}+11$ & 2.6 \\
\hline & & 1 & $3 / 2$ & $\mathrm{E} 1$ & 43.24 & 0.5 & $9.48 \mathrm{E}+10$ & 1.5 \\
\hline 30 & $1 / 2$ & 2 & $1 / 2$ & $\mathrm{E} 1$ & 62.12 & 0.8 & $1.22 \mathrm{E}+12$ & 2.5 \\
\hline 31 & $5 / 2$ & 2 & $1 / 2$ & $\mathrm{E} 1$ & 47.68 & 0.7 & $1.54 \mathrm{E}+12$ & 2.2 \\
\hline & & 1 & $3 / 2$ & $\mathrm{E} 1$ & 34.39 & 0.5 & $1.32 \mathrm{E}+09$ & 1.5 \\
\hline
\end{tabular}

on the transition energy. We do not perform that procedure in the present work because of a large scale of such calculations. The second reason giving a rise of uncertainty of transition probabilities is the inaccuracy of the calculated transition energy $\Delta E$. The accuracy of the transition energy $\Delta E$ can be determined by comparing it (or the corresponding transition wavelength $\lambda$ ) to the measured value in the case such a quantity is known. Alternatively, it can be derived from the uncertainties $U_{E_{\mathrm{i}}}$ and $U_{E_{\mathrm{f}}}$ of the calculated level energies for the initial (i) and final (f) levels of the particular transition. In this case, the absolute uncertainty of the transition energy $U_{\Delta E}$ is defined by

$$
U_{\Delta E}=\left(U_{E_{\mathrm{i}}}^{2}+U_{E_{\mathrm{f}}}^{2}\right)^{1 / 2} .
$$

Here and further we use the capital letter " $U$ " to mark the absolute uncertainties; alternatively, we use the lowercase letter " $u$ " for marking a relative uncertainty. This rule is applied both for energies and transition probabilities. In a similar way, the relative uncertainty $u_{A}$ of the theoretical transition probability $A$ due to the uncertainty of the transition energy $\Delta E$ is determined by

$$
u_{A}=\frac{A^{+}-A^{-}}{2 A}
$$

where the transition probabilities $A^{ \pm}$are defined as

$$
A^{ \pm}=A \cdot\left(\frac{\Delta E \pm U_{\Delta E}}{\Delta E}\right)^{2 k+1} .
$$

Here $k=1$ for the E1 and M1 transitions, $k=2$ for the E2 and M2 transitions, $k=3$ for the E3 transitions. The transition probability value $A$ is determined during the $\mathrm{QR}$ calculations directly from the theoretical level energies and the reduced matrix elements of the radiative transition operator. These values $A$ are listed in Tables 4-9.

In our previous work [13] we consistently and thoroughly evaluated the calculated level energies by comparing them to the experimental data and the results of other calculations. Based on those 
Table 6. Radiative transition wavelengths $\lambda$, transition probabilities $A$, their relative uncertainties $u_{\lambda}$ and $u_{A}$ (in \%) for the $\mathrm{W}^{40+}$ ion.

\begin{tabular}{|c|c|c|c|c|c|c|c|c|}
\hline$K_{\mathrm{i}}$ & $J_{\mathrm{i}}$ & $K_{\mathrm{f}}$ & $J_{\mathrm{f}}$ & Type & $\lambda(\AA)$ & $u_{\lambda}$ & $A\left(\mathrm{~s}^{-1}\right)$ & $u_{A}$ \\
\hline 2 & 0 & 1 & 2 & E2 & 1352 & 7.3 & $6.33 \mathrm{E}+00$ & 36.9 \\
\hline \multirow[t]{3}{*}{3} & 1 & 1 & 2 & M1 & 134.5 & 0.7 & $6.42 \mathrm{E}+06$ & 2.2 \\
\hline & & 2 & 0 & M1 & 149.3 & 1.1 & $2.02 \mathrm{E}+06$ & 3.4 \\
\hline & & 1 & 2 & E2 & 134.5 & 0.7 & $1.76 \mathrm{E}+05$ & 3.6 \\
\hline \multirow[t]{2}{*}{4} & 2 & 1 & 2 & M1 & 128.7 & 0.7 & $3.98 \mathrm{E}+06$ & 2.1 \\
\hline & & 1 & 2 & E2 & 128.7 & 0.7 & $2.80 \mathrm{E}+05$ & 3.5 \\
\hline 5 & 2 & 1 & 2 & E1 & 79.06 & 0.4 & $8.06 \mathrm{E}+09$ & 1.3 \\
\hline \multirow[t]{3}{*}{6} & 1 & 1 & 2 & E1 & 77.79 & 0.4 & $9.71 \mathrm{E}+09$ & 1.3 \\
\hline & & 2 & 0 & E1 & 82.53 & 0.6 & $2.91 \mathrm{E}+09$ & 1.9 \\
\hline & & 4 & 2 & E1 & 196.6 & 1.5 & $2.60 \mathrm{E}+08$ & 4.5 \\
\hline 7 & 0 & 3 & 1 & E1 & 183.2 & 1.4 & $2.90 \mathrm{E}+07$ & 4.2 \\
\hline \multirow[t]{2}{*}{8} & 3 & 1 & 2 & E1 & 77.14 & 0.4 & $9.76 \mathrm{E}+07$ & 1.2 \\
\hline & & 4 & 2 & E1 & 192.5 & 1.5 & $3.69 \mathrm{E}+06$ & 4.4 \\
\hline \multirow[t]{3}{*}{9} & 2 & 1 & 2 & E1 & 70.54 & 0.4 & $1.16 \mathrm{E}+10$ & 1.1 \\
\hline & & 3 & 1 & E1 & 148.4 & 1.1 & $1.72 \mathrm{E}+09$ & 3.4 \\
\hline & & 4 & 2 & E1 & 156.1 & 1.2 & $1.42 \mathrm{E}+09$ & 3.6 \\
\hline \multirow[t]{2}{*}{10} & 4 & 8 & 3 & M1 & 740.8 & 5.7 & $3.03 \mathrm{E}+04$ & 17.0 \\
\hline & & 1 & 2 & M2 & 69.86 & 0.4 & $7.32 \mathrm{E}+03$ & 1.9 \\
\hline 11 & 0 & 3 & 1 & M1 & 124.6 & 1.0 & $1.73 \mathrm{E}+07$ & 2.9 \\
\hline 12 & 3 & 1 & 2 & E1 & 64.68 & 0.3 & $4.46 \mathrm{E}+11$ & 1.0 \\
\hline \multirow[t]{2}{*}{13} & 1 & 1 & 2 & E1 & 64.02 & 0.3 & $1.47 \mathrm{E}+11$ & 1.0 \\
\hline & & 2 & 0 & E1 & 67.21 & 0.5 & $1.08 \mathrm{E}+11$ & 1.5 \\
\hline \multirow[t]{3}{*}{14} & 2 & 1 & 2 & E1 & 62.64 & 0.3 & $4.25 \mathrm{E}+11$ & 1.0 \\
\hline & & 3 & 1 & E1 & 117.2 & 0.9 & $1.20 \mathrm{E}+10$ & 2.7 \\
\hline & & 4 & 2 & E1 & 122.0 & 0.9 & $9.17 \mathrm{E}+09$ & 2.8 \\
\hline \multirow[t]{4}{*}{15} & 1 & 2 & 0 & E1 & 62.19 & 0.5 & $3.25 \mathrm{E}+11$ & 1.4 \\
\hline & & 1 & 2 & E1 & 59.46 & 0.3 & $2.61 \mathrm{E}+11$ & 1.0 \\
\hline & & 4 & 2 & E1 & 110.5 & 0.8 & $2.81 \mathrm{E}+10$ & 2.5 \\
\hline & & 3 & 1 & E1 & 106.6 & 0.8 & $7.75 \mathrm{E}+09$ & 2.4 \\
\hline \multirow[t]{4}{*}{16} & 1 & 1 & 2 & E1 & 50.79 & 2.9 & $2.80 \mathrm{E}+10$ & 8.7 \\
\hline & & 2 & 0 & E1 & 52.77 & 3.0 & $1.70 \mathrm{E}+10$ & 9.1 \\
\hline & & 4 & 2 & E1 & 83.90 & 4.8 & $5.22 \mathrm{E}+09$ & 14.4 \\
\hline & & 3 & 1 & E1 & 81.61 & 4.7 & $1.89 \mathrm{E}+09$ & 14.1 \\
\hline 17 & 0 & 3 & 1 & E1 & 81.54 & 4.7 & $9.86 \mathrm{E}+09$ & 14.0 \\
\hline
\end{tabular}


Table 6. (continued)

\begin{tabular}{|c|c|c|c|c|c|c|c|c|}
\hline$K_{\mathrm{i}}$ & $J_{\mathrm{i}}$ & $K_{\mathrm{f}}$ & $J_{\mathrm{f}}$ & Type & $\lambda(\AA)$ & $u_{\lambda}$ & $A\left(\mathrm{~s}^{-1}\right)$ & $u_{A}$ \\
\hline \multirow[t]{2}{*}{18} & 2 & 1 & 2 & E1 & 50.73 & 2.9 & $7.81 E+09$ & 8.7 \\
\hline & & 4 & 2 & E1 & 83.75 & 4.8 & $1.95 \mathrm{E}+09$ & 14.4 \\
\hline \multirow[t]{2}{*}{19} & 3 & 1 & 2 & E1 & 49.98 & 2.9 & $1.66 \mathrm{E}+10$ & 8.7 \\
\hline & & 4 & 2 & E1 & 81.72 & 4.8 & $1.28 \mathrm{E}+09$ & 14.3 \\
\hline \multirow[t]{2}{*}{20} & 4 & 8 & 3 & M1 & 135.0 & 8.0 & $1.09 \mathrm{E}+06$ & 24.1 \\
\hline & & 8 & 3 & E2 & 135.0 & 8.0 & $1.48 \mathrm{E}+05$ & 40.6 \\
\hline 21 & 2 & 1 & 2 & E1 & 48.07 & 2.9 & $1.13 \mathrm{E}+11$ & 8.7 \\
\hline 22 & 3 & 1 & 2 & E1 & 47.20 & 2.9 & $1.47 \mathrm{E}+11$ & 8.7 \\
\hline \multirow[t]{3}{*}{23} & 4 & 10 & 4 & M1 & 143.8 & 8.9 & $4.61 \mathrm{E}+06$ & 26.8 \\
\hline & & 12 & 3 & M1 & 172.3 & 10.7 & $1.63 \mathrm{E}+06$ & 32.1 \\
\hline & & 8 & 3 & M1 & 120.5 & 7.5 & $1.46 \mathrm{E}+05$ & 22.4 \\
\hline 24 & 0 & 3 & 1 & E1 & 71.16 & 4.5 & $1.82 \mathrm{E}+08$ & 13.4 \\
\hline \multirow[t]{2}{*}{25} & 1 & 1 & 2 & E1 & 46.52 & 2.9 & $5.71 \mathrm{E}+11$ & 8.7 \\
\hline & & 3 & 1 & E1 & 71.11 & 4.5 & $3.27 \mathrm{E}+09$ & 13.4 \\
\hline 26 & 2 & 1 & 2 & E1 & 46.46 & 2.9 & $1.77 \mathrm{E}+12$ & 8.7 \\
\hline 27 & 3 & 1 & 2 & E1 & 46.37 & 2.9 & $1.65 \mathrm{E}+12$ & 8.7 \\
\hline \multirow[t]{2}{*}{28} & 1 & 1 & 2 & E1 & 46.33 & 2.9 & $1.38 \mathrm{E}+12$ & 8.7 \\
\hline & & 2 & 0 & E1 & 47.97 & 3.0 & $3.00 \mathrm{E}+10$ & 9.0 \\
\hline \multirow[t]{6}{*}{29} & 4 & 10 & 4 & M1 & 134.9 & 8.5 & $6.99 \mathrm{E}+05$ & 25.7 \\
\hline & & 12 & 3 & M1 & 159.5 & 10.1 & $4.94 \mathrm{E}+05$ & 30.4 \\
\hline & & 10 & 4 & $\mathrm{E} 2$ & 134.9 & 8.5 & $1.04 \mathrm{E}+05$ & 43.3 \\
\hline & & 9 & 2 & E2 & 132.4 & 8.4 & $7.66 \mathrm{E}+04$ & 42.5 \\
\hline & & 19 & 3 & M1 & 580.6 & 49.7 & $2.86 \mathrm{E}+04$ & 161.5 \\
\hline & & 4 & 2 & M2 & 71.64 & 4.5 & $1.08 \mathrm{E}+04$ & 22.8 \\
\hline \multirow[t]{2}{*}{30} & 5 & 10 & 4 & M1 & 132.2 & 8.4 & $1.22 \mathrm{E}+06$ & 25.3 \\
\hline & & 10 & 4 & E2 & 132.2 & 8.4 & $1.50 \mathrm{E}+05$ & 42.7 \\
\hline \multirow[t]{3}{*}{31} & 1 & 2 & 0 & E1 & 46.53 & 3.0 & $1.70 \mathrm{E}+12$ & 9.0 \\
\hline & & 1 & 2 & E1 & 44.98 & 2.9 & $1.62 \mathrm{E}+10$ & 8.7 \\
\hline & & 3 & 1 & E1 & 67.58 & 4.4 & $1.51 \mathrm{E}+10$ & 13.1 \\
\hline \multirow[t]{4}{*}{32} & 2 & 3 & 1 & E1 & 66.34 & 4.3 & $4.07 \mathrm{E}+09$ & 13.0 \\
\hline & & 1 & 2 & E1 & 44.42 & 2.9 & $3.29 \mathrm{E}+09$ & 8.7 \\
\hline & & 1 & 2 & E1 & 44.42 & 2.9 & $3.29 \mathrm{E}+09$ & 8.7 \\
\hline & & & 2 & E1 & 67.84 & 4.4 & $1.91 \mathrm{E}+09$ & 13.3 \\
\hline 33 & 3 & 4 & 2 & E1 & 66.62 & 4.4 & $1.21 \mathrm{E}+09$ & 13.3 \\
\hline
\end{tabular}


Table 6. (continued)

\begin{tabular}{|c|c|c|c|c|c|c|c|c|}
\hline$K_{\mathrm{i}}$ & $J_{\mathrm{i}}$ & $K_{\mathrm{f}}$ & $J_{\mathrm{f}}$ & Type & $\lambda(\AA)$ & $u_{\lambda}$ & $A\left(\mathrm{~s}^{-1}\right)$ & $u_{A}$ \\
\hline & & & 2 & E1 & 43.90 & 2.9 & $4.75 \mathrm{E}+08$ & 8.7 \\
\hline \multirow[t]{3}{*}{34} & 2 & 3 & 1 & E1 & 63.79 & 4.3 & $2.85 \mathrm{E}+11$ & 12.9 \\
\hline & & 4 & 2 & E1 & 65.18 & 4.4 & $2.05 \mathrm{E}+11$ & 13.2 \\
\hline & & 1 & 2 & E1 & 43.27 & 2.9 & $5.41 \mathrm{E}+10$ & 8.7 \\
\hline \multirow[t]{4}{*}{35} & 1 & 3 & 1 & E1 & 63.28 & 4.3 & $5.40 \mathrm{E}+11$ & 12.8 \\
\hline & & 2 & 0 & E1 & 44.45 & 3.0 & $1.86 \mathrm{E}+11$ & 9.0 \\
\hline & & 1 & 2 & E1 & 43.03 & 2.9 & $4.93 \mathrm{E}+10$ & 8.7 \\
\hline & & 4 & 2 & E1 & 64.65 & 4.4 & $4.74 \mathrm{E}+10$ & 13.1 \\
\hline \multirow[t]{2}{*}{36} & 3 & 4 & 2 & E1 & 63.58 & 4.3 & $6.19 \mathrm{E}+11$ & 13.0 \\
\hline & & 1 & 2 & E1 & 42.56 & 2.9 & $4.31 \mathrm{E}+10$ & 8.7 \\
\hline \multirow[t]{3}{*}{37} & 2 & 3 & 1 & E1 & 61.41 & 4.2 & $6.15 \mathrm{E}+11$ & 12.7 \\
\hline & & 4 & 2 & E1 & 62.70 & 4.3 & $4.48 \mathrm{E}+11$ & 13.0 \\
\hline & & 1 & 2 & E1 & 42.16 & 2.9 & $2.49 \mathrm{E}+10$ & 8.7 \\
\hline 38 & 0 & 3 & 1 & E1 & 61.37 & 4.2 & $6.82 \mathrm{E}+11$ & 12.7 \\
\hline \multirow[t]{2}{*}{39} & 1 & 4 & 2 & E1 & 59.59 & 4.3 & $1.13 \mathrm{E}+12$ & 12.8 \\
\hline & & 11 & 0 & E1 & 110.0 & 7.9 & $1.97 \mathrm{E}+10$ & 23.6 \\
\hline 40 & 0 & 3 & 1 & E1 & 47.35 & 3.9 & $1.86 \mathrm{E}+12$ & 11.8 \\
\hline \multirow[t]{2}{*}{41} & 1 & 3 & 1 & E1 & 46.92 & 3.9 & $1.15 \mathrm{E}+12$ & 11.8 \\
\hline & & 4 & 2 & E1 & 47.66 & 4.0 & $3.98 \mathrm{E}+11$ & 12.0 \\
\hline 42 & 3 & 4 & 2 & E1 & 47.07 & 4.0 & $1.52 \mathrm{E}+12$ & 11.9 \\
\hline \multirow[t]{2}{*}{43} & 2 & 3 & 1 & E1 & 46.28 & 3.9 & $6.70 \mathrm{E}+11$ & 11.7 \\
\hline & & 4 & 2 & E1 & 47.01 & 4.0 & $6.66 \mathrm{E}+11$ & 11.9 \\
\hline \multirow[t]{10}{*}{44} & 4 & 23 & 4 & M1 & 123.4 & 13.0 & $6.07 \mathrm{E}+06$ & 39.1 \\
\hline & & 30 & 5 & M1 & 133.4 & 14.2 & $1.64 \mathrm{E}+06$ & 42.8 \\
\hline & & 36 & 3 & M1 & 170.2 & 18.6 & $1.34 \mathrm{E}+06$ & 56.4 \\
\hline & & 22 & 3 & M1 & 122.1 & 12.8 & $1.27 \mathrm{E}+06$ & 38.7 \\
\hline & & 29 & 4 & M1 & 130.8 & 13.9 & $8.35 \mathrm{E}+05$ & 41.9 \\
\hline & & 33 & 3 & M1 & 151.7 & 16.4 & $6.29 \mathrm{E}+05$ & 49.5 \\
\hline & & 27 & 3 & M1 & 128.1 & 13.5 & $3.33 \mathrm{E}+05$ & 40.9 \\
\hline & & 30 & 5 & $\mathrm{E} 2$ & 133.4 & 14.2 & $2.20 \mathrm{E}+05$ & 73.7 \\
\hline & & 19 & 3 & M1 & 106.8 & 11.0 & $1.55 \mathrm{E}+05$ & 33.1 \\
\hline & & 29 & 4 & $\mathrm{E} 2$ & 130.8 & 13.9 & $1.27 \mathrm{E}+05$ & 72.0 \\
\hline \multirow[t]{2}{*}{45} & 2 & 4 & 2 & E1 & 45.90 & 3.9 & $3.01 \mathrm{E}+10$ & 11.8 \\
\hline & & 3 & 1 & E1 & 45.20 & 3.9 & $1.82 \mathrm{E}+10$ & 11.7 \\
\hline \multirow[t]{2}{*}{46} & 3 & 4 & 2 & E1 & 44.98 & 3.9 & $4.65 \mathrm{E}+09$ & 11.8 \\
\hline & & 1 & 2 & E1 & 33.33 & 2.9 & $1.84 \mathrm{E}+09$ & 8.7 \\
\hline \multirow[t]{4}{*}{47} & 1 & 11 & 0 & E1 & 61.54 & 5.7 & $1.17 \mathrm{E}+12$ & 17.0 \\
\hline & & 3 & 1 & $\mathrm{E} 1$ & 41.20 & 3.8 & $4.52 \mathrm{E}+10$ & 11.4 \\
\hline & & 30 & 5 & M1 & 133.4 & 14.2 & $1.64 \mathrm{E}+06$ & 42.8 \\
\hline & & 27 & 3 & M1 & 128.1 & 13.5 & $3.33 \mathrm{E}+05$ & 40.9 \\
\hline
\end{tabular}


Table 7. Radiative transition wavelengths $\lambda$, transition probabilities $A$, their relative uncertainties $u_{\lambda}$ and $u_{A}$ (in \%) for the $\mathrm{W}^{41+}$ ion.

\begin{tabular}{|c|c|c|c|c|c|c|c|c|}
\hline$K_{\mathrm{i}}$ & $J_{\mathrm{i}}$ & $K_{\mathrm{f}}$ & $J_{\mathrm{f}}$ & Type & $\lambda(\AA ̊)$ & $u_{\lambda}$ & $A\left(\mathrm{~s}^{-1}\right)$ & $u_{A}$ \\
\hline 2 & $3 / 2$ & 1 & $3 / 2$ & M1 & 140.1 & 1.2 & $7.05 \mathrm{E}+06$ & 3.7 \\
\hline \multirow[t]{2}{*}{3} & $5 / 2$ & 1 & $3 / 2$ & M1 & 131.7 & 1.1 & $1.24 \mathrm{E}+06$ & 3.4 \\
\hline & & 1 & $3 / 2$ & E2 & 131.7 & 1.1 & $2.48 \mathrm{E}+05$ & 5.7 \\
\hline \multirow[t]{2}{*}{4} & $1 / 2$ & 1 & $3 / 2$ & M1 & 122.3 & 1.1 & $4.57 \mathrm{E}+06$ & 3.2 \\
\hline & & 1 & $3 / 2$ & E2 & 122.3 & 1.1 & $2.52 \mathrm{E}+05$ & 5.3 \\
\hline \multirow[t]{2}{*}{5} & $3 / 2$ & 1 & $3 / 2$ & E1 & 79.32 & 0.7 & $1.14 \mathrm{E}+10$ & 2.1 \\
\hline & & 3 & $5 / 2$ & E1 & 199.5 & 2.5 & $1.43 \mathrm{E}+08$ & 7.4 \\
\hline \multirow[t]{3}{*}{6} & $5 / 2$ & 1 & $3 / 2$ & E1 & 69.74 & 0.6 & $4.36 \mathrm{E}+10$ & 1.8 \\
\hline & & 2 & $3 / 2$ & E1 & 138.9 & 1.7 & $3.52 \mathrm{E}+09$ & 5.1 \\
\hline & & 3 & $5 / 2$ & E1 & 148.3 & 1.8 & $2.43 \mathrm{E}+09$ & 5.5 \\
\hline \multirow[t]{6}{*}{7} & $3 / 2$ & 2 & $3 / 2$ & M1 & 121.4 & 1.5 & $9.18 \mathrm{E}+06$ & 4.5 \\
\hline & & 3 & $5 / 2$ & M1 & 128.4 & 1.6 & $2.17 \mathrm{E}+06$ & 4.7 \\
\hline & & 4 & $1 / 2$ & M1 & 138.8 & 1.7 & $1.77 \mathrm{E}+06$ & 5.1 \\
\hline & & 3 & $5 / 2$ & E2 & 128.4 & 1.6 & $4.73 \mathrm{E}+05$ & 7.9 \\
\hline & & 5 & $3 / 2$ & E1 & 360.7 & 4.4 & $1.40 \mathrm{E}+05$ & 13.3 \\
\hline & & 2 & $3 / 2$ & E2 & 121.4 & 1.5 & $1.09 \mathrm{E}+05$ & 7.5 \\
\hline \multirow[t]{3}{*}{8} & $5 / 2$ & 1 & $3 / 2$ & E1 & 64.60 & 0.6 & $2.88 \mathrm{E}+11$ & 1.7 \\
\hline & & 2 & $3 / 2$ & E1 & 119.9 & 1.5 & $1.06 \mathrm{E}+10$ & 4.4 \\
\hline & & 3 & $5 / 2$ & E1 & 126.8 & 1.6 & $6.70 \mathrm{E}+09$ & 4.7 \\
\hline \multirow[t]{2}{*}{9} & $1 / 2$ & 1 & $3 / 2$ & E1 & 61.24 & 0.5 & $2.33 \mathrm{E}+11$ & 1.6 \\
\hline & & 4 & $1 / 2$ & E1 & 122.6 & 1.5 & $2.92 \mathrm{E}+10$ & 4.5 \\
\hline \multirow[t]{3}{*}{10} & $3 / 2$ & 1 & $3 / 2$ & E1 & 60.55 & 0.5 & $4.61 \mathrm{E}+11$ & 1.6 \\
\hline & & 3 & $5 / 2$ & E1 & 112.1 & 1.4 & $3.44 \mathrm{E}+10$ & 4.1 \\
\hline & & 2 & $3 / 2$ & E1 & 106.7 & 1.3 & $1.20 \mathrm{E}+10$ & 3.9 \\
\hline \multirow[t]{3}{*}{11} & $5 / 2$ & 3 & $5 / 2$ & E1 & 82.43 & 1.3 & $6.58 \mathrm{E}+09$ & 4.0 \\
\hline & & 1 & $3 / 2$ & E1 & 50.70 & 0.7 & $2.82 \mathrm{E}+09$ & 2.1 \\
\hline & & 2 & $3 / 2$ & E1 & 79.45 & 1.3 & $1.55 \mathrm{E}+08$ & 3.9 \\
\hline \multirow[t]{4}{*}{12} & $3 / 2$ & 1 & $3 / 2$ & E1 & 50.67 & 0.7 & $4.89 \mathrm{E}+10$ & 2.1 \\
\hline & & 3 & $5 / 2$ & E1 & 82.35 & 1.3 & $6.69 \mathrm{E}+09$ & 4.0 \\
\hline & & 2 & $3 / 2$ & E1 & 79.37 & 1.3 & $3.82 \mathrm{E}+09$ & 3.9 \\
\hline & & 4 & $1 / 2$ & E1 & 86.48 & 1.4 & $1.94 \mathrm{E}+09$ & 4.2 \\
\hline \multirow[t]{3}{*}{13} & $1 / 2$ & 1 & $3 / 2$ & E1 & 50.60 & 0.7 & $4.58 \mathrm{E}+09$ & 2.1 \\
\hline & & 2 & $3 / 2$ & E1 & 79.22 & 1.3 & $4.41 \mathrm{E}+09$ & 3.9 \\
\hline & & 4 & $1 / 2$ & E1 & 86.30 & 1.4 & $1.52 \mathrm{E}+09$ & 4.2 \\
\hline 14 & $7 / 2$ & 3 & $5 / 2$ & E1 & 79.49 & 1.3 & $2.47 \mathrm{E}+08$ & 4.0 \\
\hline 15 & $7 / 2$ & 3 & $5 / 2$ & E1 & 73.08 & 1.3 & $7.46 \mathrm{E}+08$ & 3.8 \\
\hline \multirow[t]{2}{*}{16} & $5 / 2$ & 1 & $3 / 2$ & E1 & 46.95 & 0.7 & $1.49 \mathrm{E}+12$ & 2.1 \\
\hline & & 2 & $3 / 2$ & E1 & 70.63 & 1.2 & $1.18 \mathrm{E}+10$ & 3.7 \\
\hline 17 & $3 / 2$ & 2 & $3 / 2$ & E1 & 70.55 & 1.2 & $1.39 \mathrm{E}+10$ & 3.7 \\
\hline
\end{tabular}


Table 7. (continued)

\begin{tabular}{|c|c|c|c|c|c|c|c|c|}
\hline$K_{\mathrm{i}}$ & $J_{\mathrm{i}}$ & $K_{\mathrm{f}}$ & $J_{\mathrm{f}}$ & Type & $\lambda(\AA)$ & $u_{\lambda}$ & $A\left(\mathrm{~s}^{-1}\right)$ & $u_{A}$ \\
\hline & & 1 & $3 / 2$ & E1 & 46.92 & 0.7 & $6.35 \mathrm{E}+09$ & 2.1 \\
\hline & & 3 & $5 / 2$ & E1 & 72.89 & 1.3 & $1.65 \mathrm{E}+09$ & 3.8 \\
\hline 18 & $3 / 2$ & 1 & $3 / 2$ & E1 & 46.75 & 0.7 & $1.95 \mathrm{E}+12$ & 2.1 \\
\hline 19 & $1 / 2$ & 1 & $3 / 2$ & E1 & 46.60 & 0.7 & $1.62 \mathrm{E}+12$ & 2.1 \\
\hline \multirow[t]{4}{*}{20} & $5 / 2$ & 1 & $3 / 2$ & E1 & 46.22 & 0.7 & $7.91 \mathrm{E}+10$ & 2.1 \\
\hline & & 3 & $5 / 2$ & E1 & 71.20 & 1.2 & $2.66 \mathrm{E}+10$ & 3.7 \\
\hline & & 2 & $3 / 2$ & E1 & 68.97 & 1.2 & $5.76 \mathrm{E}+09$ & 3.6 \\
\hline & & 7 & $3 / 2$ & E1 & 159.8 & 2.8 & $1.28 \mathrm{E}+09$ & 8.4 \\
\hline \multirow[t]{4}{*}{21} & $9 / 2$ & 6 & $5 / 2$ & E2 & 134.5 & 2.4 & $7.22 \mathrm{E}+04$ & 11.8 \\
\hline & & 14 & $7 / 2$ & M1 & 624.9 & 13.0 & $4.73 \mathrm{E}+04$ & 39.2 \\
\hline & & 8 & $5 / 2$ & $\mathrm{E} 2$ & 158.9 & 2.8 & $2.37 \mathrm{E}+04$ & 14.0 \\
\hline & & 3 & $5 / 2$ & M2 & 70.52 & 1.2 & $6.82 \mathrm{E}+03$ & 6.2 \\
\hline 22 & $7 / 2$ & 3 & $5 / 2$ & E1 & 65.40 & 1.2 & $4.70 \mathrm{E}+11$ & 3.6 \\
\hline \multirow[t]{3}{*}{23} & $5 / 2$ & 2 & $3 / 2$ & E1 & 63.45 & 1.2 & $6.98 \mathrm{E}+11$ & 3.5 \\
\hline & & 1 & $3 / 2$ & E1 & 43.67 & 0.7 & $1.13 \mathrm{E}+11$ & 2.1 \\
\hline & & 3 & $5 / 2$ & E1 & 65.34 & 1.2 & $2.19 \mathrm{E}+10$ & 3.6 \\
\hline \multirow[t]{4}{*}{24} & $3 / 2$ & 2 & $3 / 2$ & E1 & 63.38 & 1.2 & $1.71 \mathrm{E}+11$ & 3.5 \\
\hline & & 4 & $1 / 2$ & E1 & 67.84 & 1.2 & $9.41 \mathrm{E}+10$ & 3.7 \\
\hline & & 3 & $5 / 2$ & E1 & 65.26 & 1.2 & $5.12 \mathrm{E}+10$ & 3.6 \\
\hline & & 1 & $3 / 2$ & E1 & 43.64 & 0.7 & $2.36 \mathrm{E}+10$ & 2.1 \\
\hline \multirow[t]{3}{*}{25} & $1 / 2$ & 2 & $3 / 2$ & E1 & 62.92 & 1.2 & $2.19 \mathrm{E}+11$ & 3.5 \\
\hline & & 4 & $1 / 2$ & E1 & 67.30 & 1.2 & $1.59 \mathrm{E}+11$ & 3.7 \\
\hline & & 1 & $3 / 2$ & E1 & 43.42 & 0.7 & $3.60 \mathrm{E}+10$ & 2.1 \\
\hline \multirow[t]{3}{*}{26} & $3 / 2$ & 2 & $3 / 2$ & E1 & 61.57 & 1.1 & $3.90 \mathrm{E}+11$ & 3.4 \\
\hline & & 3 & $5 / 2$ & E1 & 63.35 & 1.2 & $1.15 \mathrm{E}+11$ & 3.5 \\
\hline & & 4 & $1 / 2$ & E1 & 65.77 & 1.2 & $1.10 \mathrm{E}+11$ & 3.7 \\
\hline \multirow[t]{2}{*}{27} & $5 / 2$ & 3 & $5 / 2$ & E1 & 61.63 & 1.2 & $6.17 \mathrm{E}+11$ & 3.5 \\
\hline & & 7 & $3 / 2$ & E1 & 118.5 & 2.2 & $1.58 \mathrm{E}+10$ & 6.7 \\
\hline \multirow[t]{4}{*}{28} & $3 / 2$ & 3 & $5 / 2$ & E1 & 58.76 & 1.1 & $6.64 \mathrm{E}+11$ & 3.4 \\
\hline & & 4 & $1 / 2$ & $\mathrm{E} 1$ & 60.84 & 1.2 & $2.79 \mathrm{E}+11$ & 3.5 \\
\hline & & 7 & $3 / 2$ & E1 & 108.3 & 2.1 & $2.41 \mathrm{E}+10$ & 6.3 \\
\hline & & 2 & $3 / 2$ & E1 & 57.23 & 1.1 & $1.95 \mathrm{E}+10$ & 3.3 \\
\hline \multirow[t]{4}{*}{29} & $1 / 2$ & 4 & $1 / 2$ & E1 & 60.72 & 1.2 & $7.54 \mathrm{E}+11$ & 3.5 \\
\hline & & 2 & $3 / 2$ & E1 & 57.13 & 1.1 & $3.40 \mathrm{E}+11$ & 3.3 \\
\hline & & 7 & $3 / 2$ & E1 & 107.9 & 2.1 & $2.44 \mathrm{E}+10$ & 6.3 \\
\hline & & 1 & $3 / 2$ & E1 & 40.58 & 0.7 & $1.96 \mathrm{E}+10$ & 2.1 \\
\hline \multirow[t]{2}{*}{30} & $3 / 2$ & 2 & $3 / 2$ & E1 & 46.99 & 1.0 & $1.13 \mathrm{E}+12$ & 3.1 \\
\hline & & 3 & $5 / 2$ & E1 & 48.02 & 1.0 & $3.75 \mathrm{E}+11$ & 3.1 \\
\hline
\end{tabular}


Table 7. (continued)

\begin{tabular}{|c|c|c|c|c|c|c|c|c|}
\hline$K_{\mathrm{i}}$ & $J_{\mathrm{i}}$ & $K_{\mathrm{f}}$ & $J_{\mathrm{f}}$ & Type & $\lambda(\AA)$ & $u_{\lambda}$ & $A\left(\mathrm{~s}^{-1}\right)$ & $u_{A}$ \\
\hline & & 4 & $1 / 2$ & E1 & 49.40 & 1.1 & $1.02 \mathrm{E}+11$ & 3.2 \\
\hline 31 & $1 / 2$ & 2 & $3 / 2$ & E1 & 46.93 & 1.0 & $1.42 \mathrm{E}+12$ & 3.1 \\
\hline \multirow[t]{2}{*}{32} & $5 / 2$ & 3 & $5 / 2$ & E1 & 47.86 & 1.0 & $8.03 \mathrm{E}+11$ & 3.1 \\
\hline & & 2 & $3 / 2$ & E1 & 46.84 & 1.0 & $5.77 \mathrm{E}+11$ & 3.1 \\
\hline 33 & $7 / 2$ & 3 & $5 / 2$ & E1 & 47.44 & 1.0 & $1.24 \mathrm{E}+12$ & 3.1 \\
\hline 34 & $7 / 2$ & 3 & $5 / 2$ & E1 & 46.52 & 1.0 & $1.17 \mathrm{E}+11$ & 3.1 \\
\hline \multirow[t]{6}{*}{35} & $9 / 2$ & 21 & $9 / 2$ & M1 & 135.4 & 3.4 & $3.18 \mathrm{E}+06$ & 10.4 \\
\hline & & 15 & $7 / 2$ & M1 & 126.8 & 3.2 & $2.61 \mathrm{E}+06$ & 9.6 \\
\hline & & 22 & $7 / 2$ & M1 & 159.3 & 4.1 & $1.88 \mathrm{E}+06$ & 12.4 \\
\hline & & 14 & $7 / 2$ & M1 & 111.3 & 2.8 & $1.34 \mathrm{E}+05$ & 8.3 \\
\hline & & 21 & $9 / 2$ & $\mathrm{E} 2$ & 135.4 & 3.4 & $1.32 \mathrm{E}+05$ & 17.3 \\
\hline & & 15 & $7 / 2$ & $\mathrm{E} 2$ & 126.8 & 3.2 & $1.26 \mathrm{E}+05$ & 16.1 \\
\hline \multirow[t]{4}{*}{36} & $1 / 2$ & 2 & $3 / 2$ & E1 & 45.37 & 1.0 & $8.73 \mathrm{E}+09$ & 3.0 \\
\hline & & 7 & $3 / 2$ & E1 & 72.46 & 1.6 & $8.59 \mathrm{E}+09$ & 4.8 \\
\hline & & 4 & $1 / 2$ & E1 & 47.61 & 1.1 & $1.61 \mathrm{E}+09$ & 3.2 \\
\hline & & 1 & $3 / 2$ & E1 & 34.27 & 0.7 & $8.40 \mathrm{E}+08$ & 2.1 \\
\hline 37 & $3 / 2$ & 4 & $1 / 2$ & E1 & 47.23 & 1.1 & $1.27 \mathrm{E}+12$ & 3.2 \\
\hline \multirow[t]{3}{*}{38} & $5 / 2$ & 1 & $3 / 2$ & E1 & 33.05 & 0.7 & $1.47 \mathrm{E}+09$ & 2.1 \\
\hline & & 2 & $3 / 2$ & E1 & 43.25 & 1.0 & $2.42 \mathrm{E}+08$ & 3.0 \\
\hline & & 3 & $5 / 2$ & E1 & 44.12 & 1.0 & $1.44 \mathrm{E}+08$ & 3.0 \\
\hline \multirow[t]{3}{*}{39} & $3 / 2$ & 7 & $3 / 2$ & E1 & 64.14 & 1.5 & $7.21 \mathrm{E}+11$ & 4.5 \\
\hline & & 4 & $1 / 2$ & E1 & 43.87 & 1.0 & $4.19 \mathrm{E}+10$ & 3.1 \\
\hline & & 3 & $5 / 2$ & E1 & 42.78 & 1.0 & $1.11 \mathrm{E}+10$ & 3.0 \\
\hline 40 & $5 / 2$ & 7 & $3 / 2$ & E1 & 62.72 & 1.5 & $1.03 \mathrm{E}+12$ & 4.4 \\
\hline 41 & $1 / 2$ & 7 & $3 / 2$ & E1 & 58.55 & 1.4 & $1.44 \mathrm{E}+12$ & 4.3 \\
\hline
\end{tabular}

comparisons, we can establish $U_{E_{\mathrm{i}}}$ and $U_{E_{\mathrm{f}}}$ The energy levels of all six studied tungsten ions can be split into two parts according to their energies. This is a common feature of the ions with an open $4 \mathrm{p}^{N}$ shell in the ground configuration. For the investigated ions, we can split levels at $E=1800000 \mathrm{~cm}^{-1}$. The first part includes the levels of the ground configuration and some low-lying levels originating from the excited configurations.

In the case of ions $\mathrm{W}^{38+}-\mathrm{W}^{43+}$, the experimental energies are available for a larger part of the levels from the first group. Consequently we can determine the values of $U_{E}$ by averaging the absolute differences between the QR and experimental lev- el energies. Further, the determined absolute uncertainty $U_{E}$ is assumed to be the same for every level from the first part (or lower group). As a special case, we consider $U_{E}=0$ for the ground level.

The second part consists of higher levels with $E>1800000 \mathrm{~cm}^{-1}$. The experimental energies are determined only for very few levels from this part; thus we cannot determine $U_{E}$ in the same way as for the levels from the first part. At the start, we determine relative uncertainties for those levels where the experimental energy values are available. Further we average the calculated relative uncertainties and assume that to be the same relative uncertainty $u_{E}$ for all levels of this part (higher 
Table 8. Radiative transition wavelengths $\lambda$, transition probabilities $A$, their relative uncertainties $u_{\lambda}$ and $u_{A}$ (in \%) for the $\mathrm{W}^{42+}$ ion.

\begin{tabular}{|c|c|c|c|c|c|c|c|c|}
\hline$K_{\mathrm{i}}$ & $J_{\mathrm{i}}$ & $K_{\mathrm{f}}$ & $J_{\mathrm{f}}$ & Type & $\lambda(\AA)$ & $u_{\lambda}$ & $A\left(\mathrm{~s}^{-1}\right)$ & $u_{A}$ \\
\hline 2 & 1 & 1 & 0 & M1 & 136.3 & 0.4 & $5.00 \mathrm{E}+06$ & 1.1 \\
\hline 3 & 2 & 1 & 0 & E2 & 129.5 & 0.3 & $1.55 \mathrm{E}+05$ & 1.7 \\
\hline \multirow[t]{2}{*}{4} & 2 & 2 & 1 & E1 & 127.9 & 0.5 & $1.34 \mathrm{E}+10$ & 1.4 \\
\hline & & 3 & 2 & E1 & 134.6 & 0.5 & $1.08 \mathrm{E}+10$ & 1.5 \\
\hline \multirow[t]{4}{*}{5} & 2 & 2 & 1 & M1 & 124.6 & 0.5 & $4.42 \mathrm{E}+06$ & 1.4 \\
\hline & & 3 & 2 & M1 & 130.9 & 0.5 & $4.18 \mathrm{E}+06$ & 1.4 \\
\hline & & 3 & 2 & E2 & 130.9 & 0.5 & $2.87 \mathrm{E}+05$ & 2.4 \\
\hline & & 2 & 1 & $\mathrm{E} 2$ & 124.6 & 0.5 & $1.45 \mathrm{E}+05$ & 2.3 \\
\hline \multirow[t]{2}{*}{6} & 0 & 2 & 1 & M1 & 113.7 & 0.4 & $1.08 \mathrm{E}+07$ & 1.3 \\
\hline & & 3 & 2 & E2 & 118.9 & 0.4 & $6.24 \mathrm{E}+05$ & 2.2 \\
\hline \multirow[t]{2}{*}{7} & 1 & 1 & 0 & E1 & 61.08 & 0.2 & $3.08 \mathrm{E}+11$ & 0.5 \\
\hline & & 3 & 2 & E1 & 115.6 & 0.4 & $3.67 \mathrm{E}+10$ & 1.3 \\
\hline \multirow[t]{2}{*}{8} & 2 & 3 & 2 & E1 & 82.79 & 0.5 & $1.05 \mathrm{E}+10$ & 1.6 \\
\hline & & 2 & 1 & E1 & 80.23 & 0.5 & $8.42 \mathrm{E}+08$ & 1.6 \\
\hline 9 & 1 & 1 & 0 & E1 & 47.09 & 0.3 & $1.66 \mathrm{E}+12$ & 0.9 \\
\hline \multirow[t]{3}{*}{10} & 2 & 2 & 1 & E1 & 70.14 & 0.5 & $3.30 \mathrm{E}+10$ & 1.5 \\
\hline & & 3 & 2 & E1 & 72.09 & 0.5 & $7.04 \mathrm{E}+09$ & 1.5 \\
\hline & & 5 & 2 & E1 & 160.5 & 1.1 & $1.25 \mathrm{E}+09$ & 3.4 \\
\hline \multirow[t]{2}{*}{11} & 3 & 3 & 2 & E1 & 70.29 & 0.5 & $8.64 \mathrm{E}+10$ & 1.5 \\
\hline & & 5 & 2 & E1 & 151.9 & 1.1 & $1.95 \mathrm{E}+09$ & 3.2 \\
\hline \multirow[t]{2}{*}{12} & 2 & 2 & 1 & E1 & 64.19 & 0.5 & $4.95 \mathrm{E}+11$ & 1.4 \\
\hline & & 3 & 2 & E1 & 65.82 & 0.5 & $2.09 \mathrm{E}+10$ & 1.5 \\
\hline \multirow[t]{2}{*}{13} & 3 & 3 & 2 & E1 & 64.29 & 0.5 & $2.73 \mathrm{E}+11$ & 1.4 \\
\hline & & 5 & 2 & E1 & 126.4 & 0.9 & $1.38 \mathrm{E}+10$ & 2.8 \\
\hline 14 & 0 & 2 & 1 & E1 & 61.69 & 0.5 & $2.52 \mathrm{E}+11$ & 1.4 \\
\hline \multirow[t]{5}{*}{15} & 1 & 2 & 1 & E1 & 59.64 & 0.5 & $3.66 \mathrm{E}+11$ & 1.4 \\
\hline & & 3 & 2 & E1 & 61.04 & 0.5 & $4.33 \mathrm{E}+10$ & 1.4 \\
\hline & & 1 & 0 & E1 & 41.49 & 0.3 & $1.84 \mathrm{E}+10$ & 0.9 \\
\hline & & 6 & 0 & E1 & 125.4 & 1.0 & $1.25 \mathrm{E}+10$ & 2.9 \\
\hline & & 5 & 2 & E1 & 114.4 & 0.9 & $1.00 \mathrm{E}+10$ & 2.6 \\
\hline \multirow[t]{2}{*}{16} & 2 & 3 & 2 & E1 & 60.23 & 0.5 & $6.67 \mathrm{E}+11$ & 1.4 \\
\hline & & 5 & 2 & E1 & 111.6 & 0.9 & $2.45 \mathrm{E}+10$ & 2.6 \\
\hline \multirow[t]{3}{*}{17} & 1 & 3 & 2 & E1 & 59.83 & 0.5 & $5.67 \mathrm{E}+11$ & 1.4 \\
\hline & & 2 & 1 & E1 & 58.48 & 0.5 & $3.29 \mathrm{E}+11$ & 1.4 \\
\hline & & 5 & 2 & E1 & 110.2 & 0.9 & $2.06 \mathrm{E}+10$ & 2.6 \\
\hline \multirow[t]{2}{*}{18} & 2 & 3 & 2 & E1 & 48.21 & 0.4 & $8.51 \mathrm{E}+11$ & 1.3 \\
\hline & & 2 & 1 & E1 & 47.33 & 0.4 & $6.47 \mathrm{E}+11$ & 1.3 \\
\hline
\end{tabular}


Table 8. (continued)

\begin{tabular}{cccccccccccc}
\hline$K_{\mathrm{i}}$ & $J_{\mathrm{i}}$ & $K_{\mathrm{f}}$ & $J_{\mathrm{f}}$ & Type & $\lambda(\AA)$ & $u_{\lambda}$ & $A\left(\mathrm{~s}^{-1}\right)$ & $u_{A}$ \\
\hline 19 & 1 & 2 & 1 & $\mathrm{E} 1$ & 47.10 & 0.4 & $1.11 \mathrm{E}+12$ & 1.3 \\
\hline & & 3 & 2 & $\mathrm{E} 1$ & 47.97 & 0.4 & $1.77 \mathrm{E}+11$ & 1.3 \\
\hline 20 & 0 & 2 & 1 & $\mathrm{E} 1$ & 46.97 & 0.4 & $1.24 \mathrm{E}+12$ & 1.3 \\
\hline 21 & 3 & 3 & 2 & $\mathrm{E} 1$ & 47.76 & 0.4 & $1.19 \mathrm{E}+12$ & 1.3 \\
\hline 22 & 4 & 11 & 3 & $\mathrm{M} 1$ & 136.4 & 1.5 & $3.16 \mathrm{E}+06$ & 4.5 \\
\hline & & 13 & 3 & M1 & 166.5 & 1.9 & $8.63 \mathrm{E}+05$ & 5.6 \\
\hline 23 & 2 & 5 & 2 & E1 & 71.58 & 0.7 & $3.98 \mathrm{E}+10$ & 2.0 \\
\hline & & 2 & 1 & E1 & 45.46 & 0.4 & $1.09 \mathrm{E}+09$ & 1.3 \\
\hline 24 & 3 & 5 & 2 & E1 & 64.71 & 0.6 & $7.72 \mathrm{E}+11$ & 1.9 \\
\hline & & 3 & 2 & E1 & 43.30 & 0.4 & $3.71 \mathrm{E}+10$ & 1.2 \\
\hline 25 & 1 & 6 & 0 & E1 & 67.60 & 0.7 & $2.45 \mathrm{E}+11$ & 2.0 \\
\hline & & 5 & 2 & E1 & 64.28 & 0.6 & $2.01 \mathrm{E}+11$ & 1.9 \\
\hline & & 3 & 2 & E1 & 43.11 & 0.4 & $1.04 \mathrm{E}+10$ & 1.2 \\
\hline 26 & 2 & 5 & 2 & E1 & 61.01 & 0.6 & $8.50 \mathrm{E}+11$ & 1.8 \\
\hline 27 & 1 & 5 & 2 & E1 & 57.36 & 0.6 & $7.53 \mathrm{E}+11$ & 1.8 \\
\hline & & 6 & 0 & E1 & 59.99 & 0.6 & $6.10 \mathrm{E}+11$ & 1.8 \\
\hline
\end{tabular}

Table 9. Radiative transition wavelengths $\lambda$, transition probabilities $A$, their relative uncertainties $u_{\lambda}$ and $u_{A}$ (in \%) for the $\mathrm{W}^{43+}$ ion.

\begin{tabular}{cccccccccc|c}
\hline$K_{\mathrm{i}}$ & $J_{\mathrm{i}}$ & $K_{\mathrm{f}}$ & $J_{\mathrm{f}}$ & Type & $\lambda(\AA)$ & $u_{\lambda}$ & $A\left(\mathrm{~s}^{-1}\right)$ & $u_{\mathrm{A}}$ \\
\hline 2 & $1 / 2$ & 1 & $1 / 2$ & $\mathrm{E} 1$ & 128.1 & 0.1 & $3.11 \mathrm{E}+10$ & 0.3 \\
\hline 3 & $3 / 2$ & 1 & $1 / 2$ & $\mathrm{M} 1$ & 126.4 & 0.1 & $4.46 \mathrm{E}+06$ & 0.3 \\
\hline & & 1 & $1 / 2$ & $\mathrm{E} 2$ & 126.4 & 0.1 & $2.34 \mathrm{E}+05$ & 0.6 \\
\hline 4 & $3 / 2$ & 3 & $3 / 2$ & $\mathrm{E} 1$ & 148.5 & 0.2 & $2.69 \mathrm{E}+09$ & 0.6 \\
\hline 5 & $5 / 2$ & 3 & $3 / 2$ & $\mathrm{E} 1$ & 134.9 & 0.2 & $1.54 \mathrm{E}+10$ & 0.5 \\
\hline 6 & $3 / 2$ & 1 & $1 / 2$ & $\mathrm{E} 1$ & 61.28 & 0.1 & $3.47 \mathrm{E}+11$ & 0.2 \\
\hline & & 3 & $3 / 2$ & $\mathrm{E} 1$ & 119.0 & 0.2 & $2.15 \mathrm{E}+10$ & 0.5 \\
\hline 7 & $1 / 2$ & 1 & $1 / 2$ & $\mathrm{E} 1$ & 60.55 & 0.1 & $6.81 \mathrm{E}+11$ & 0.2 \\
\hline & & 3 & $3 / 2$ & $\mathrm{E} 1$ & 116.3 & 0.1 & $2.99 \mathrm{E}+10$ & 0.4 \\
\hline 8 & $3 / 2$ & 1 & $1 / 2$ & $\mathrm{E} 1$ & 47.97 & 0.2 & $1.23 \mathrm{E}+12$ & 0.5 \\
\hline 9 & $5 / 2$ & 3 & $3 / 2$ & $\mathrm{E} 1$ & 70.83 & 0.2 & $8.79 \mathrm{E}+10$ & 0.7 \\
\hline 10 & $5 / 2$ & 3 & $3 / 2$ & $\mathrm{E} 1$ & 64.31 & 0.2 & $5.10 \mathrm{E}+11$ & 0.7 \\
\hline 11 & $1 / 2$ & 3 & $3 / 2$ & $\mathrm{E} 1$ & 60.59 & 0.2 & $4.92 \mathrm{E}+11$ & 0.7 \\
\hline 12 & $3 / 2$ & 3 & $3 / 2$ & $\mathrm{E} 1$ & 59.50 & 0.2 & $1.04 \mathrm{E}+12$ & 0.7 \\
\hline
\end{tabular}

group). To conclude, we determine the absolute This value is exploited in Eq. (3) to determine value of uncertainty for each level from this group. the uncertainties $U_{\Delta E}$ for transition energies (or Thus $U_{E}$ depends on the level energy: $U_{E}=u_{E} \cdot E$. wavelengths). 
Tables 4-9 list the calculated QR wavelengths $\lambda$ and transition probabilities $A$ along with their relative uncertainties $u_{\lambda}$ and $u_{A}$ for the investigated tungsten ions.

\section{4. $W^{38+}$}

For the lower-level group of excited levels of this ion, we establish the $U_{E}=4700 \mathrm{~cm}^{-1}$, and for the higherlevel group $u_{E}=0.2 \%$. The $\mathrm{W}^{38+}$ ion is a rather specific one as the ground configuration has a closed outer shell and, consequently, only one level. Therefore the most part of radiative transitions, which are the M1 transitions, occur among the levels of the excited configurations (see Table 4. We can group these transitions according to their wavelengths or transition energies. For the first group of transitions, $\lambda<180 \AA$, and the average $u_{A}=2.8 \%$. The second group of transitions has $500<\lambda<900 \AA$ with the average uncertainties $u_{A}=14.1 \%$. For the M1 transitions from the level $K=5$, the wavelengths $\lambda>2500 \AA$, and the uncertainties of transition probabilities are even larger. Those transitions along with the M2 transition $\left(u_{A}=1.8 \%\right)$ to the ground level define a total radiative lifetime $\tau$ of this metastable level with an exceptionally large lifetime $\tau$. Another prominent level with a large lifetime is level $K=4$; its lifetime is determined by the E3 transition with $u_{A}=2.6 \%$. The average uncertainties for the E1 transition probabilities are equal to $0.9 \%$.

The comparison of the QR and MCDHF [20] level energies for the ion $\mathrm{W}^{38+}$ with the data from the NIST database [8] reveals that the values from the MCDHF calculation are slightly closer to those from the NIST. In most cases, the MCDHF radiative lifetimes are to some degree smaller compared to our $\tau$ values, only the levels that have the M2 and E3 radiative decay channels display an exception. As it was demonstrated in [31], one has to include the higher-multipole order radiative transitions from the metastable levels of excited configurations in order to determine correctly the total radiative lifetime $\tau$.

\section{5. $W^{39+}$}

After splitting the energy spectra of the $\mathrm{W}^{39+}$, we determine $U_{E}=6600 \mathrm{~cm}^{-1}$ for the lower-level group and $u_{E}=0.5 \%$ for the higher-level group. For the E1 transitions the average relative uncertainty $u_{A}=1.9 \%$. For the M1 transitions with $\lambda<200 \AA$ the averaged $u_{A}=4.9 \%$. For the M1 transitions among highly-excited levels, the $u_{A}$ can reach $20 \%$ and more since their $U_{\Delta E}$ are significantly larger compared to other M1 transitions. There are two allowed M2 transitions from the metastable levels $K=6$ and $K=9$, and their transition probability uncertainties $u_{A} \approx 2.5 \%$. The lifetime $\tau$ of the $K=6 \mathrm{lev}$ el strongly depends on the M2 transition. The radiative lifetime value increases by more than a factor of three if this transition is omitted in calculation.

\section{6. $W^{40+}$}

Three investigated configurations of the $W^{40+}$ ion produce the largest number of the levels among all studied ions in the present work. The analysis of the lower-level energies determines $U_{E}=5400 \mathrm{~cm}^{-1}$. For the higher-level group $u_{E}=2.9 \%$. This value of the relative uncertainty is unusually large in the context of the present and other our studies. Based on these estimations of uncertainty values, we can determine that the averaged $u_{A}$ is almost 9\% for the E1 transitions. This value drops to $2.5 \%$ for the E1 transitions among the levels from the lower group. That value is similar to the uncertainty estimation for other studied ions.

For the M1 transitions, the average $u_{A}$ is almost 35\%. For the transitions between the levels of the lower group, the average $u_{A}=5.5 \%$. For the E2 transitions among the ground configuration levels, $u_{A} \approx 4 \%$; only one line with a large wavelength makes an exception. This type of transitions among the excited configuration levels has significantly higher $u_{A}$ values.

Considering the higher levels of the $W^{40+}$ ion, we can notice that their $U_{E}$ values are exceptionally large in comparison to the higher levels of other studied ions. Meanwhile, for the lower levels, it is very similar to $U_{E}$ of other studied tungsten ions. Therefore we assume that our level assignment of the experimental energies in [13] can be erroneous for few levels from the higher group.

\section{7. $W^{41+}$}

For the $\mathrm{W}^{41+}$ ion, we determine $U_{E}=8700 \mathrm{~cm}^{-1}$ for the lower levels and $u_{E}=0.7 \%$ for the higher levels. The average $u_{A} \approx 3.5 \%$ for the E1 transitions. 
The M1 transitions among the ground configuration levels have the average $u_{A}=4.1 \%$, whereas the average uncertainty $u_{A}$ for the M1 transitions among the levels of the excited configuration levels is $16 \%$ due to the larger transition wavelengths. The investigated excited configurations have two metastable levels, $K=21$ and $K=35$. The radiative lifetime of the level $K=21$ is defined by the E2 transition with $u_{A}=11.8 \%$. The uncertainties $u_{A}$ of other E2 transitions from the higher levels are $~ 15 \%$ whereas $u_{A} \approx 6 \%$ for the E2 transitions among the ground configuration levels.

\section{8. $W^{42+}$ and $W^{43+}$}

The calculated QR level energies for the ions $\mathrm{W}^{42+}$ and $\mathrm{W}^{43+}$ agree exceptionally well with the experimental values. Therefore uncertainties of transition probabilities are noticeably smaller compared to those for other studied tungsten ions of the lower ionization stages.

For the $\mathrm{W}^{42+}$ ion, we determine $U_{E}=2600 \mathrm{~cm}^{-1}$ for the group of lower levels. Meanwhile, $u_{E}=0.3 \%$ for the higher levels. The average $u_{A}=1.7 \%$ for the E1 transitions. It is equal to $2.5 \%$ for the $\mathrm{M} 1$ transitions. The $\mathrm{E} 2$ transition is possible only from the level $K=3$. It has $u_{A}=1.7 \%$, and the average uncertainties of other E2 transitions are 2.3\%.

The uncertainties for the $\mathrm{W}^{43+}$ ion, which has only one pelectron in the outer shell of the ground configuration, are the smallest ones among all studied ions. For the group of lower levels, $U_{E}=900 \mathrm{~cm}^{-1}$, whereas $u_{E}=0.15 \%$ for the higher levels. The average uncertainty for all types of transitions $u_{A}=0.5 \%$.

\section{Summary and conclusions}

The quasirelativistic approximation was used to determine radiative transition data for the multicharged tungsten ions having an open $4 \mathrm{p}^{N}$ shell in the ground configuration. This work displays the level energies $E$, their radiative lifetimes $\tau$, and the radiative rates $A$ for the emission transitions of the E1, M1, M2, E2, and E3 types from the excited levels of the configurations $4 \mathrm{~s}^{2} 4 \mathrm{p}^{N}, 4 \mathrm{~s}^{2} 4 \mathrm{p}^{N-1} 4 \mathrm{~d}$ and $4 \mathrm{~s} 4 \mathrm{p}^{N+1}$ in the $\mathrm{W}^{38+}-\mathrm{W}^{43+}$ ions.

A complete set of spectroscopic parameters for these configurations of the tungsten ions is pre- sented for the first time. Only the ion $W^{39+}$ has been comprehensively studied by us [7] and other authors [12] previously.

We describe the methods applied to determine the uncertainties $u_{A}$ of radiative transition probabilities arising from the uncertainties of calculated level energies. Their relative values $u_{\lambda}$ and $u_{A}$ are presented along with the $\mathrm{QR}$ wavelengths and transition probabilities for the tungsten ions $\mathrm{W}^{38+}-\mathrm{W}^{43+}$.

The uncertainties of the E1 transitions vary from 0.5 to $3.5 \%$. The largest average uncertainties occur for the E1 transitions in $\mathrm{W}^{40+}$ and $\mathrm{W}^{41+}$ ions as their energy level spectra are most complex among the studied ions. In order to improve the accuracy of radiative transition data, one needs to perform additional studies for these ions. The average uncertainties of the M1 transitions range from 3 to $20 \%$; they noticeably depend on the transition wavelength. The uncertainties for the E3 and M2 transitions do not exceed $10 \%$.

The present study demonstrates that it is necessary to calculate the transition probabilities of higher multipole order, M2 and E3 in addition to more usual E1, M1, and E2 in order to determine reliable radiative lifetimes for the excited levels of tungsten ions.

The comparison of our calculated QR wavelengths and transition probabilities with high quality MCDF calculation results for the ground configuration levels demonstrates that the QR and MCDF values are very close. That gives us reason to believe that our results are reliable and accurate enough for the two lowest excited configurations. Further, the high accuracy and reliability of the QR results are confirmed by comparison with the existing wavelength measurements for the transitions from excited configurations. The uncertainties of the wavelengths and transition probabilities presented in this work also validate the accuracy of the spectroscopic parameters calculated for the investigated excited configurations.

The complete set of data on the radiative transitions and the parameters of the electron-impact excitation can be found in the ADAMANT database (http://www.adamant.tfai.vu.lt/database) either in an user-friendly or in a machine readable form. 


\section{References}

[1] J. Reader, Spectral data for fusion energy: from $W$ to W, Phys. Scr. T134, 014023 (2009), https://doi. org/10.1088/0031-8949/2009/T134/014023

[2] C. Skinner, Atomic physics in the quest for fusion energy and ITER, Phys. Scr. T134, 014022 (2009), https://doi.org/10.1088/0031-8949/2009 T134/014022

[3] P. Beiersdorfer, J. Clementson, and U.I. Safronova, Tungsten data for current and future uses in fusion and plasma science, Atoms 3, 260-272 (2015), https://doi.org/10.3390/atoms3020260

[4] Z. Wu, Y. Fu, X. Ma, M. Li, L. Xie, J. Jiang, and C. Dong, Electron impact excitation and dielectronic recombination of highly charged tungsten ions, Atoms 3, 474-494 (2015), https://doi. org/10.3390/atoms3040474

[5] P. Bogdanovich and R. Kisielius, Theoretical energy level spectra and transition data for $4 \mathrm{p}^{6} 4 \mathrm{~d}$, $4 \mathrm{p}^{6} 4 \mathrm{f}$ and $4 \mathrm{p}^{5} 4 \mathrm{~d}^{2}$ configurations of $\mathrm{W}^{37+}$ ion, At. Data Nucl. Data Tables 98, 557-565 (2012), https://doi.org/10.1016/j.adt.2011.11.004

[6] P. Bogdanovich and R. Kisielius, Theoretical energy level spectra and transition data for $4 \mathrm{p}^{6} 4 \mathrm{~d}^{2}$, $4 \mathrm{p}^{6} 4 \mathrm{~d}^{4} \mathrm{f}$, and $4 \mathrm{p}^{5} 4 \mathrm{~d}^{3}$ configurations of $\mathrm{W}^{36+}$, At. Data Nucl. Data Tables 99, 580-594 (2013), https://doi.org/10.1016/j.adt.2012.11.001

[7] P. Bogdanovich, R. Karpuškienė, and R. Kisielius, Quasirelativistic calculation of $4 \mathrm{~s}^{2} 4 \mathrm{p}^{5}, 4 \mathrm{~s}^{2} 4 \mathrm{p}^{4} 4 \mathrm{~d}$ and $4 \mathrm{~s}^{4} \mathrm{p}^{6}$ configuration spectroscopic parameters for the $\mathrm{W}^{39+}$ ion, Phys. Scr. 90, 035401 (2015), https://doi.org/10.1088/0031-8949/90/3/035401

[8] A. Kramida, Yu. Ralchenko, J. Reader, and NIST ASD Team. NIST Atomic Spectra Database, Version 5.3 (National Institute of Standards and Technology, Gaithersburg, MD, USA, 2015), https://physics.nist.gov/asd

[9] S.B. Utter, P. Beiersdorfer, and E. Träbert, Electron-beam ion-trap spectra of tungsten in the EUV, Can. J. Phys. 80, 1503-1515 (2002), https://doi.org/10.1139/p02-132

[10]R. Radtke, C. Biedermann, G. Fussmann, J.L. Schwob, P. Mandelbaum, and R. Doron, Measured line spectra and calculated atomic physics data for highly charged tungsten ions, in: Atomic and Plasma-Material Interaction Data for
Fusion, Vol. 13, ed. R.E.H. Clark (International Atomic Energy Agency, Vienna, 2007) pp. 45-66.

[11]K.M. Aggarwal and F.P. Keenan, Energy levels, radiative rates, and lifetimes for transitions in W XL, At. Data Nucl. Data Tables 100, 1399-1518 (2014), https://doi.org/10.1016/j.adt.2014.02.006

[12]C. Froese Fischer, Evaluation and comparison of the configuration interaction calculations for complex atoms, Atoms 2, 1-14 (2014), https://doi.org/10.3390/atoms2010001

[13]P. Bogdanovich, R. Karpuškienè, and R. Kisielius, Energyspectraofthetungstenion $4 \mathrm{~s}^{2} 4 \mathrm{p}^{N}, 4 \mathrm{~s}^{2} 4 \mathrm{p}^{N-1} 4 \mathrm{~d}$ and $4 \mathrm{~s} 4 \mathrm{p}^{N+1}$ configurations, Lith. J. Phys. 55, 162 (2015), https://doi.org/10.3952/physics. v55i3.3145

[14] K.B. Fournier, Atomic data and spectral line intensities for highly ionized tungsten (Co-like $\mathrm{W}^{47+}$ to $\mathrm{Rb}$-like $\mathrm{W}^{37+}$ ) in a high-temperature, low-density plasma, At. Data Nucl. Data Tables 68, 1-48 (1998), https://doi.org/10.1006/adnd.1997.0756

[15]P. Quinet, A theoretical survey of atomic structure and forbidden transitions in the $4 \mathrm{p}^{k}$ and $4 \mathrm{~d}^{k}$ ground configurations of tungsten ions $\mathrm{W}^{29+}$ through $\mathrm{W}^{43+}$, J. Phys. B 45, 025003 (2012), https://doi.org/10.1088/0953-4075/45/2/025003

[16]P. Quinet, É. Biémont, P. Palmeri, and E. Träbert, Multiconfiguration Dirac-Fock wavelengths and transition rates in the $\mathrm{X}$-ray spectra of highly charged Ga-like ions from $\mathrm{Yb}^{39+}$ to $\mathrm{U}^{61+}$, At. Data Nucl. Data Tables 93, 167-182 (2007), https://doi.org/10.1016/j.adt.2006.09.001

[17]F. Hu, C. Wang, J. Yang, G. Jiang, and L. Hao, Multiconfiguration Dirac-Fock calculations of transition probabilities of some tungsten ions, Phys. Scr. 84, 015302 (2011), https://doi.org/10.1088/0031-8949/84/01/015302

[18]L.-H. Hao and X.-P. Kang, Energy levels and spectral lines in the X-ray spectra of highly charged W XLIV, Eur. Phys. J. D 68, 203 (2014), https://doi.org/10.1140/epjd/e2014-50056-0

[19]J. Clementson, P. Beiersdorfer, T. Brage, and M.F. $\mathrm{Gu}$, Atomic data and theoretical X-ray spectra of Ge-like through V-like W ions, At. Data Nucl. Data Tables 100, 577-649 (2014), https://doi.org/10.1016/j.adt.2013.07.002

[20]G. Gaigalas, P. Rynkun, and C. Froese Fischer, Lifetimes of $4 \mathrm{p}^{5} 4 \mathrm{~d}$ levels in highly ionized 
atoms, Phys. Rev. A 91, 022509 (2015), https://doi.org/10.1103/PhysRevA.91.022509

[21]A. Kramida, Critical evaluation of data on atomic energy levels, wavelengths, and transition probabilities, Fusion Sci. Technol. 63, 313323 (2013), https://doi.org/10.13182/FST13-A16437

[22]A. Kramida, Assessing uncertainties of theoretical atomic transition probabilities with Monte Carlo random trials, Atoms 2, 86-122 (2014), https://doi.org/10.3390/atoms2020086

[23]P. Bogdanovich and O. Rancova, Quasirelativistic approach for $a b$ initio study of highly charged ions, Phys. Scr. 78, 045301 (2008), https://doi.org/10.1088/0031-8949/78/04/045301

[24]P. Bogdanovich and O. Rancova, Quasirelativistic Hartree-Fock equations consistent with BreitPauli approach, Phys. Rev. A 74(5), 052501 (2006), https://doi.org/10.1103/PhysRevA.74.052501

[25]P. Bogdanovich and O. Rancova, Adjustment of the quasirelativistic equations for $p$ electrons, Phys. Rev. A 76, 012507 (2007), https://doi. org/10.1103/PhysRevA.76.012507

[26]P. Bogdanovich and R. Karpuškienè, Numerical methods of the preliminary evaluation of the role of admixed configurations in atomic calculations, Comp. Phys. Comm. 134, 321-334 (2001), https://doi.org/10.1016/S0010-4655(00)00214-9

[27]P. Bogdanovich, R. Karpuškienè, and A. Momkauskaite, Some problems of calculation of en- ergy spectra of complex atomic configurations, Comput. Phys. Commun. 143, 174-180 (2002), https://doi.org/10.1016/S0010-4655(01)00446-5

[28]A. Hibbert, R. Glass, and C. Froese Fischer, A general program for computing angular integrals of the Breit-Pauli Hamiltonian, Comput. Phys. Commun. 64, 445-472 (1991), https://doi. org/10.1016/0010-4655(91)90138-B

[29]C. Froese Fischer, M.R. Godefroid, and A. Hibbert, A program for performing angular integrations for transition operators, Comput. Phys. Commun. 64, 486-500 (1991), https://doi. org/10.1016/0010-4655(91)90140-G

[30]C. Froese Fischer and M.R. Godefroid, Programs for computing $L S$ and $L S J$ transitions from MCHF wave functions, Comput. Phys. Commun. 64, 501-519 (1991), https://doi.org/10.1016/00104655(91)90141-7

[31]R. Karpuškienè, P. Bogdanovich, and R. Kisielius, Significance of $M 2$ and E3 transitions for $4 p^{5} 4 d^{N+1}$ - and $4 p^{6} 4 d^{N-1} 4 f$-configuration metastable-level lifetimes, Phys. Rev. A 88, 022519 (2013), https://doi.org/10.1103/PhysRevA.88.022519

[32] A. Bar-Shalom, M. Klapisch, and J. Oreg, Electron collision excitations in complex spectra of ionized heavy atoms, Phys. Rev. A 38, 1773-1784 (1988), https://doi.org//10.1103/PhysRevA.38.1773

\title{
RADIACINIAI ŠUOLIAI TARP TRIJŲ ŽEMIAUSIUU KONFIGŪRACIJŲ LYGMENŲ VOLFRAMO JONUOSE $\mathrm{W}^{38+}-\mathrm{W}^{43+}$
}

\author{
R. Karpuškiene, P. Bogdanovičius, R. Kisielius \\ Vilniaus universiteto Teorinés fizikos ir astronomijos institutas, Vilnius, Lietuva
}

\begin{abstract}
Santrauka
Kvazireliatyvistinis Hartrio ir Foko artinys panaudotas tiriant radiacinių šuolių savybes volframo jonuose $\mathrm{W}^{38+}-\mathrm{W}^{43+}$ su atviru $4 \mathrm{p}$ sluoksniu. Konfigūracijų sąveikos artejimas pritaikytas koreliaciniams efektams iskaityti naudojant transformuotujuc radialiujuc orbitalių bazę. Darbe pateikiamos konfigūracijų $4 \mathrm{~s}^{2} 4 \mathrm{p}^{N}, 4 \mathrm{~s}^{2} 4 \mathrm{p}^{N-1} 4 \mathrm{~d}$
\end{abstract}

ir $4 \mathrm{~s} 4 \mathrm{p}^{N+1}$ lygmenų energijos, jų radiacinès gyvavimo trukmès $\tau$, Landé $g$-daugikliai bei ịvairių tipų (E1, E2, E3, M1 ir M2) savaiminių šuolių bangų ilgiai ir emisijos šuolių tikimybės. Gautos šuolių charakteristikos palygintos su eksperimentiniais ir kitų autorių teoriniais duomenimis. Kartu pateikiami teorinių bangų ilgių neapibrèžtumai ir iš jų kylantys šuolių tikimybių neapibrèžtumai. 